\title{
Smad phosphoisoform signals in acute and chronic liver injury: similarities and differences between epithelial and mesenchymal cells
}

\author{
Koichi Matsuzaki
}

Received: 7 March 2011 / Accepted: 15 April 2011 /Published online: 31 May 2011

(C) The Author(s) 2011. This article is published with open access at Springerlink.com

\begin{abstract}
Hepatocellular carcinoma (HCC) usually arises from hepatic fibrosis caused by chronic inflammation. In chronic liver damage, hepatic stellate cells undergo progressive activation to myofibroblasts (MFB), which are important extracellular-matrix-producing mesenchymal cells. Concomitantly, perturbation of transforming growth factor (TGF)- $\beta$ signaling by pro-inflammatory cytokines in the epithelial cells of the liver (hepatocytes) promotes both fibrogenesis and carcinogenesis (fibro-carcinogenesis). Insights into fibro-carcinogenic effects on chronically damaged hepatocytes have come from recent detailed analyses of the TGF- $\beta$ signaling process. Smad proteins, which convey signals from TGF- $\beta$ receptors to the nucleus, have intermediate linker regions between conserved Mad homology (MH) 1 and MH2 domains. TGF- $\beta$ type I receptor and pro-inflammatory cytokine-activated kinases differentially phosphorylate Smad2 and Smad3 to create phosphoisoforms phosphorylated at the $\mathrm{COOH}$-terminal, linker, or both $(\mathrm{L} / \mathrm{C})$ regions. After acute liver injury, TGF$\beta$-mediated pSmad3C signaling terminates hepatocytic proliferation induced by the pro-inflammatory cytokinemediated mitogenic pSmad3L pathway; TGF- $\beta$ and proinflammatory cytokines synergistically enhance collagen synthesis by activated hepatic stellate cells via $\mathrm{pSmad} 2 \mathrm{~L} / \mathrm{C}$ and $\mathrm{pSmad} 3 \mathrm{~L} / \mathrm{C}$ pathways. During chronic liver disease progression, pre-neoplastic hepatocytes persistently affected
\end{abstract}

The author's work is supported financially by the Ministry of Education, Science and Culture of Japan.

\section{K. Matsuzaki $(\bowtie)$}

Department of Gastroenterology and Hepatology,

Kansai Medical University,

10-15 Fumizonocho, Moriguchi,

Osaka 570-8506, Japan

e-mail:matsuzak@takii.kmu.ac.jp by TGF- $\beta$ together with pro-inflammatory cytokines come to exhibit the same carcinogenic (mitogenic) pSmad3L and fibrogenic $\mathrm{pSmad} 2 \mathrm{~L} / \mathrm{C}$ signaling as do MFB, thereby accelerating liver fibrosis while increasing risk of HCC. This review of Smad phosphoisoform-mediated signals examines similarities and differences between epithelial and mesenchymal cells in acute and chronic liver injuries and considers Smad linker phosphorylation as a potential target for the chemoprevention of fibro-carcinogenesis.

Keywords TGF- $\beta$-Smad $\cdot$ JNK $\cdot$ Liver fibrosis . Hepatic carcinogenesis
Abbreviations
ActRI
Activin type I receptor
CDK
Cyclin-dependent kinase
CTGF
Connective tissue growth factor
ECM
Extracellular matrix
EMT Epithelial-to-mesenchymal transition
ERK Extracellular signal-regulated kinase
HBV Hepatitis B virus
$\mathrm{HCV}$ Hepatitis $C$ virus
$\mathrm{HCC}$ Hepatocellular carcinoma
HSC Hepatic stellate cells
JNK c-Jun N-terminal kinase
IL Interleukin
MAPK Mitogen-activated protein kinase
MFB Myofibroblast
MH Mad-homology
MKK Mitogen-activated kinase kinase
PAI Plasminogen activator inhibitor
PDGF Platelet-derived growth factor
pSmadC C-terminally phosphorylated Smad
pSmadL Linker phosphorylated Smad 
pSmadL/C Dually phosphorylated Smad

SMA Smooth muscle actin

TGF Transforming growth factor

T $\beta$ RI TGF- $\beta$ type I receptor

TNF Tumor necrosis factor

\section{Introduction}

The incidence of hepatocellular carcinoma (HCC) is rising in North America, Europe, and Eastern countries such as China (El-Serag and Rudolph 2007). This increase is largely attributable to the emergence of hepatitis $\mathrm{C}$ virus $(\mathrm{HCV})$ and to continued difficulties with the control of hepatitis B virus (HBV) infection (Koike 2002; Llovet et al. 2003). The inflammatory response triggered by hepatitis viral infection is part of the normal host defense, whose goal is pathogen elimination. However, carcinogenic pathogens subvert host immunity and establish persistent infections associated with low-grade chronic inflammation. If hepatitis viruses are not cleared in the acute phase of infection, the patients can develop chronic hepatitis. Some patients subsequently develop liver fibrosis as a result of chronic liver damage, characterized by extracellular matrix (ECM) accumulation that distorts hepatic architecture by forming a fibrous scar (Friedman 2010). Ultimately, nodules of regenerating hepatocytes become enclosed by scar tissue, an event defining cirrhosis. As human livers infected by hepatitis viruses progress from chronic hepatitis to cirrhosis, HCC occurrence increases (Tsukuma et al. 1993). Most HCC cases have a natural history of unresolved inflammation and severe fibrosis (or cirrhosis) irrespective of the underlying cause of liver disease (Omata and Yoshida 2004). Approaches to understanding the way that human HCC develops in chronic liver diseases should therefore focus on molecular mechanisms shared in common between fibrosis and carcinogenesis (fibro-carcinogenesis) caused by chronic inflammation.

After acute liver injury, mesenchymal cells including hepatic stellate cells (HSC) activated by transforming growth factor (TGF)- $\beta$ and pro-inflammatory cytokines promote tissue remodeling by deposition of a collagen-rich ECM (Friedman 2010). The seemingly key roles of TGF- $\beta$ in liver fibrosis argue for the application of TGF- $\beta$ inhibitors in the treatment of chronic liver diseases. However, in order to maintain liver homeostasis after acute liver injury, TGF- $\beta$ activity is needed to terminate the proliferation of hepatocytes, the epithelial cells of the liver, induced by pro-inflammatory cytokine-mediated mitogenic signaling. In this respect, TGF- $\beta$ has received serious consideration as a candidate tumor-suppressive cytokine during chronic liver diseases (Derynck and Miyazono 2008).
Before clinical attempts of the blockage of fibrogenic TGF- $\beta$ signaling in human chronic liver disorders, we need to study the way that TGF- $\beta$ signaling is perturbed by proinflammatory cytokines during human chronic liver diseases in which hepatocytes, together with HSC, induce fibrocarcinogenesis. Consideration should also be given to the physiologic roles of TGF- $\beta$ and pro-inflammatory cytokine signals, which differ between regenerative hepatocytes and collagen-producing HSC after acute liver injury.

The TGF- $\beta$ superfamily is composed of many multifunctional cytokines, including TGF- $\beta$, activin, and bone morphogenic protein (Roberts and Sporn 1990; Derynck and Miyazono 2008). Progress over the past 10 years has disclosed important details of the manner in which the TGF- $\beta$ family elicits its responses (Heldin et al. 1997; Wrana 2000; Shi and Massagué 2003; Guo and Wang 2009). Smads, central mediators conveying signals from receptors for TGF- $\beta$ superfamily members to the nucleus, are modular proteins with conserved Mad-homology (MH) 1, intermediate linker, and $\mathrm{MH} 2$ domains (Shi and Massagué 2003). In cell-signaling pathways, various transcription factors are phosphorylated at multiple sites by upstream kinases. Catalytically active TGF- $\beta$ type I receptor (T $\beta R I)$ and activin type I receptor (ActRI) phosphorylate $\mathrm{COOH}$-tail serine residues of receptoractivated Smad (R-Smad), which include Smad2 and the highly similar protein Smad3 (Wrana 2000). Mitogenic signals alternatively cause the phosphorylation of R-Smad at specific sites in its middle linker regions (Kretzschmar et al. 1999; Mori et al. 2004; Matsuura et al. 2004; Kamaraju and Roberts 2005; Sekimoto et al. 2007; Matsuzaki et al. 2009). Once phosphorylated R-Smad has rapidly oligomerized with Smad4, this complex translocates to the nucleus, where it regulates the transcription of target genes.

Monitoring of the phosphorylation status of signaling molecules is a key step in dissecting their pathways. In Smad signaling, the phosphorylation of not only the $\mathrm{COOH}$-tail, but also the linker regions of R-Smad is likely to be important in regulating Smad activity under physiologic and pathologic conditions (Liu 2006). In this review, we first examine Smad signaling specificity derived from the spatial and temporal dynamics of domain-specific R-Smad phosphorylation in response to TGF- $\beta$ and/or pro-inflammatory cytokines. We next consider the way in which these phosphorylated R-Smad signals determine specific cellular responses to TGF- $\beta$ /proinflammatory cytokines in hepatocytes and HSC after acute liver injury. Then, we examine the phosphorylated R-Smad signals shared by both hepatocytes and HSC in chronic liver injury, by which these cells continuously transmit a fibrocarcinogenic signal. Finally, we consider how the enhanced understanding of phosphorylated R-Smad signaling could lead to improved methods for the prevention of human fibro-carcinogenesis. 


\section{Various cells activated after liver injury}

A complex interplay among the various hepatic cell types takes place in injured livers (Fig. 1). Hepatocytes are targets for most hepatotoxic agents, including hepatitis viruses, alcohol metabolites, and chemical toxins (Taub 2004). Damaged hepatocytes induce the recruitment of white blood cells by local inflammatory cells. Apoptosis of damaged hepatocytes stimulates fibrogenesis by Kupffer cells, the resident macrophages of the liver. Activated Kupffer cells secrete pro-inflammatory cytokines including tumor necrosis factor (TNF)- $\alpha$ and interleukins (IL), plus TGF- $\beta$. Intensive studies have shown that HSC are the major cell type responsible for matrix production in damaged liver tissues (Pinzani and Macias-Barragan 2010). HSC, characterized by retinoid droplets in the cytoplasm, are present in the space of Disse (Friedman 2010). After liver injury, activated HSC secrete large amounts of ECM proteins.

Hepatic fibrosis results from a wound-healing response to repeated liver injury (Bataller and Brenner 2005). HSC undergo a dramatic phenotypic activation in chronic liver diseases, with the acquisition of fibrogenic properties.
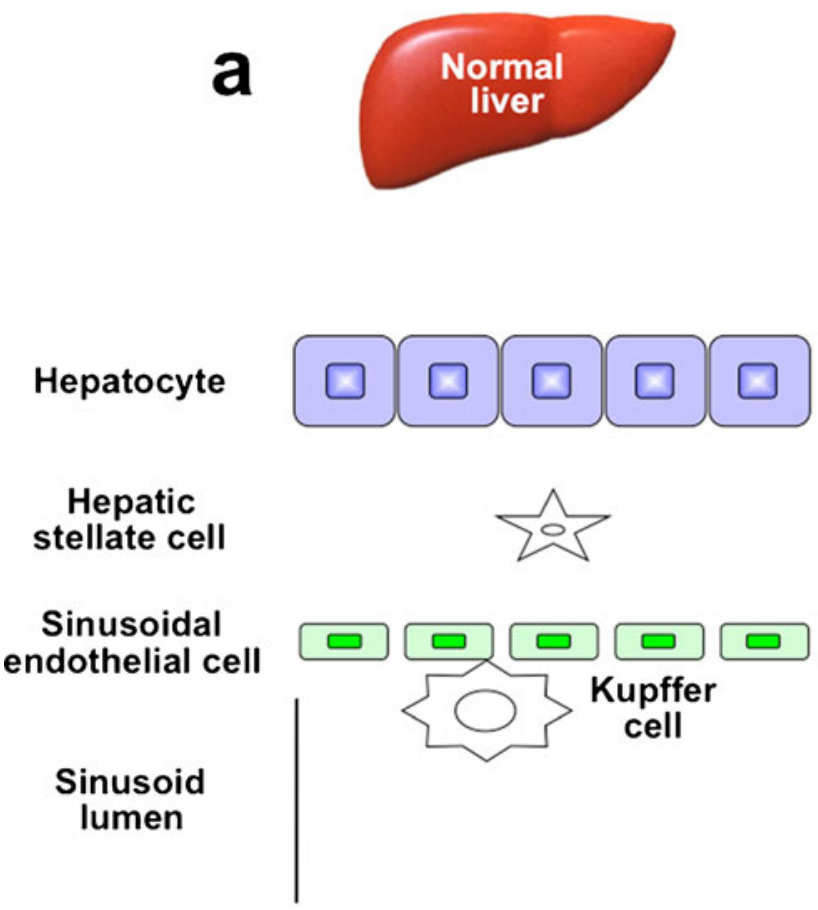

\section{Sinusoidal endothelial cell}

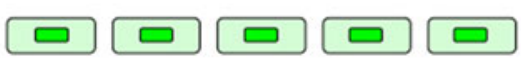

Fig. 1 Changes in hepatic architecture (a) associated with advanced hepatic fibrosis (b). Following liver injury, lymphocytes infiltrate the hepatic parenchyma. Some hepatocytes undergo apoptosis, and Kupffer cells are activated to release fibrogenic mediators such as transforming growth factor- $\beta(T G F-\beta)$ and tumor necrosis factor- $\alpha(T N F-\alpha)$. In response to these cytokines, hepatic stellate cells (HSC) transdifferentiate
Hepatic mesenchymal cell types other than activated HSC also have fibrogenic potential: portal fibroblasts of bone marrow origin have been identified as collagen-producing cells in injured livers (Ramadori and Saile 2004). The distribution of fibrous material depends upon the etiology of liver injury. In chronic viral hepatitis and chronic cholestatic disorders, fibrosis originates in periportal regions, whereas in alcohol-induced liver disease and after $\mathrm{CCl}_{4}$ intoxication, fibrosis is pericentral. Hepatocytes are replaced with abundant ECM, mainly in the form of fibrillar collagen. Sinusoidal endothelial cells lose their fenestrations, and tonic contraction of HSC increases resistance to blood flow in the hepatic sinusoids.

A new concept has been proposed that epithelial cells undergo a phenotypical change called epithelial-mesenchymal transition (EMT) to acquire a fibroblastic phenotype. EMT is a mechanism that facilitates metastasis and cancer development (Weinberg 2007). Pioneering studies of EMT in the field of organ fibrosis have been accomplished in the kidney, lens, and lung (Iwano et al. 2002; Saika et al. 2004). EMT has also been postulated to promote liver fibrosis. Zeisberg et al. (2007) have demonstrated that hepatocytes acquire the expression of fibroblast specific protein 1 in response to
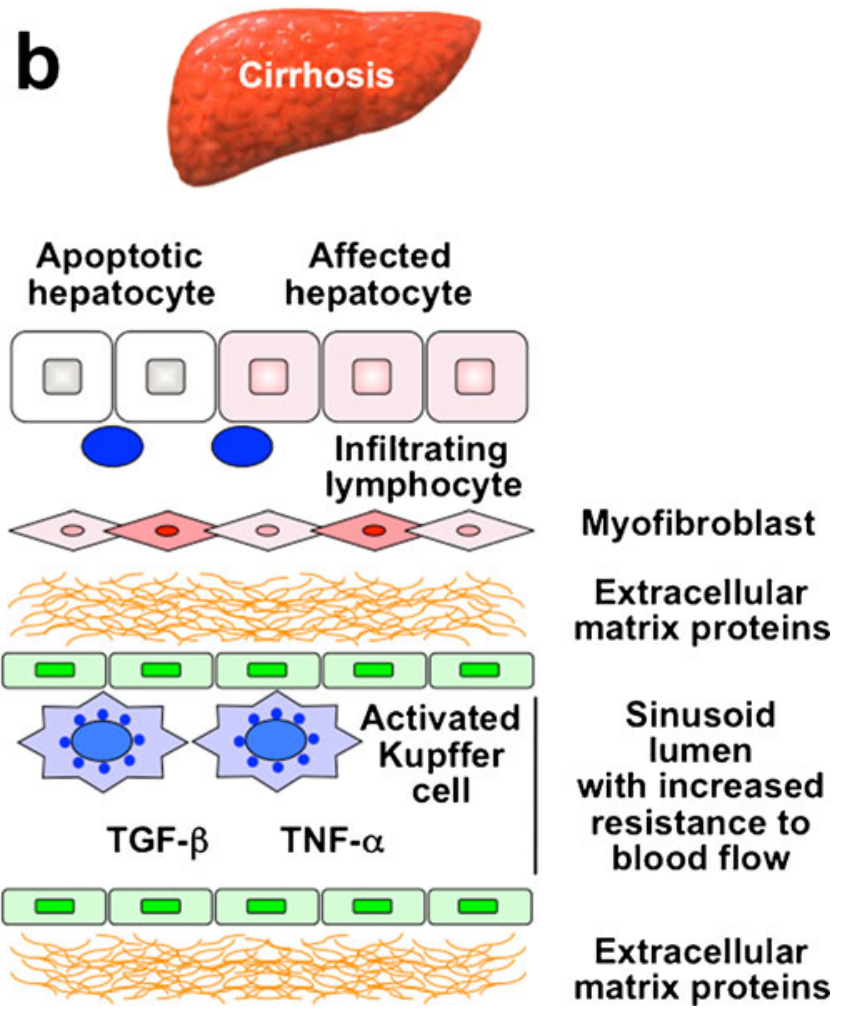

into myofibroblast-like cells and come to secrete large amounts of extracellular material (ECM) proteins. Affected hepatocytes also participate in liver fibrogenesis by stimulating the deposition of ECM proteins. As liver fibrosis progresses, sinusoidal endothelial cells lose their fenestrations, with tonic contraction of HSC increasing resistance to blood flow in hepatic sinusoids 
$\mathrm{CCl}_{4}$ in vivo or to TGF- $\beta$ in vitro. In addition, cholangiocytes have been suggested to undergo EMT (Omenetti et al. 2008). However, recent studies indicate that hepatocytes and cholangiocytes do not contribute directly to the fibrogenic myofibroblast population in liver fibrosis via EMT (Taura et al. 2010; Scholten et al. 2010). Thus, the controversy over the concept of EMT in fibrotic diseases, conceived in genetic mouse models, is far from being resolved (Popov and Schuppan 2010).

\section{Multiple Smad phosphoisoforms exist}

The canonical TGF- $\beta$ /activin pathway involves Smad 2 and Smad3 signaling through direct serine phosphorylation of COOH-termini by T $\beta$ RI/ActRI upon the TGF- $\beta$ /activin binding (Shi and Massagué 2003; Derynck and Miyazono 2008; Fig. 2a). TßRI/ActRI-mediated phosphorylation of Smad2 and Smad3 induces their association with the shared partner Smad4, followed by translocation into the nucleus where these complexes activate transcription of specific genes (Heldin et al. 1997; Wrana 2000; Shi and Massagué 2003; Derynck and Miyazono 2008; Guo and Wang 2009). Smad proteins contain a conserved Mad-homology (MH)1 domain that binds DNA, and a conserved MH2 domain that binds receptors, partner Smad4, and transcription coactivators.

More divergent linker regions separate the two domains (Shi and Massagué 2003). The linker domain undergoes regulatory phosphorylation by mitogen-activated protein kinase (MAPK) pathways including extracellular signalregulated kinase (ERK), c-Jun N-terminal kinase (JNK), p38 MAPK, and cyclin-dependent kinase (CDK)-2/4, and glycogen synthase kinase $3-\beta, \mathrm{Ca}(2+)$-calmodulin-dependent protein kinase II, and G-protein-coupled receptor kinase-2 (Kretzschmar et al. 1999; Wicks et al. 2000; Furukawa et al. 2003; Mori et al. 2004; Matsuura et al. 2004; Kamaraju and Roberts 2005; Ho et al. 2005; Millet et al. 2009; Matsuzaki et al. 2009; Alarcón et al. 2009; Fig. 2b). TGF- $\beta$ also elicits signaling responses through non-Smad pathways that are generally considered as important effecter pathways for TGF$\beta$ activated kinase (TAK) 1 in response to pro-inflammatory cytokines (Fig. 2a). TAK1 activates JNK and p38 MAPK signaling through mitogen-activated kinase kinase (MKK) 4/ 7 and MKK3/6 (Akira and Takeda 2004; Shim et al. 2005). JNK and p38 MAPK have been linked to the modification of TGF- $\beta$ signaling by pro-inflammatory cytokines through their regulation of distinct processes, such as cytoskeleton organization, cell growth, survival, migration, or invasion (Xu et al. 2009). Imbalance might occur between signaling through non-Smad and Smad pathways during fibrocarcinogenesis, and interaction between these pathways mediates pro-fibrogenic and pro-tumorigenic effects of TGF- $\beta$ (Derynck and Akhurst 2007).
The use of mice with a targeted deletion of Smad3 and JNK1 as a down-stream mediator of TAK1 indicates that both Smad3 and JNK1 pathways involve hepatic fibrocarcinogesis. When acute liver injury is induced by the administration of $\mathrm{CCl}_{4}, \mathrm{Smad}_{3}{ }^{--}$mice show approximately one-half of the induction of collagen type I mRNA as do wild-type mice (Schnabl et al. 2001). In $J N K 1^{-/-}$mice, not only liver fibrosis, but also HCC development is prevented. A remarkable collagen deposition in wild-type and $J N K 2^{-/}$ mice, but less deposition in $J N K 1^{-/}$mice, suggests an important role for JNK1 in the development of liver fibrosis

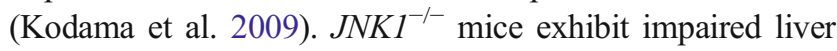
carcinogenesis with reduced tumor masses, sizes, and

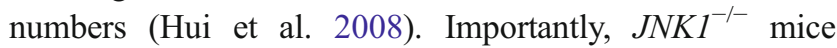
display decreased HCC proliferation in a carcinogenic model and decreased hepatocytic growth in a model of liver regeneration. In both cases, the impaired proliferation is caused by the increased expression of $\mathrm{p} 21^{\mathrm{WAF} 1}$, a cell-cycle inhibitor, and the reduced expression of c-Myc, a negative regulator of $\mathrm{p} 21^{\mathrm{WAF} 1}$.

Pro-inflammatory cytokines simultaneously activate linkerphosphorylated R-Smad and non-Smad signaling, with both usually operating in parallel. The biological significance of linker-phosphorylated R-Smad pathways is therefore difficult to assess in isolation. Here, we will review recent work in this area, with a particular focus on the way that the proinflammatory cytokines modulate TGF- $\beta$ signaling through R-Smad linker phosphorylation, by using hepatic fibrocarcinogenesis as an example. Antibodies (Abs) reactive with structurally related phosphorylated peptides are emerging as valuable tools for determining phosphorylation sites in vivo and for investigating their distinct signals via phosphorylated domains. Domain-specific phospho-R-Smad Abs have allowed us to reveal that T $\beta R I / A c t R I$ and JNK/CDK4 differentially phosphorylate R-Smad to create three phosphorylated forms (phosphoisoforms): $\mathrm{COOH}$-terminally phosphorylated R-Smad (pSmad2C and pSmad3C), linker phosphorylated R-Smad (pSmad2L and pSmad3L), and dually phosphorylated R-Smad (pSmad2L/C and pSmad3L/C; Matsuzaki 2006, 2009; Sapkota et al. 2006; Wrighton et al. 2009). Except for pSmad2L with its cytoplasmic localization (Kretzschmar et al. 1999; Yamagata et al. 2005), the other phosphoisoforms are localized to the cell nuclei (Furukawa et al. 2003; Mori et al. 2004; Yamagata et al. 2005; Yoshida et al. 2005; Sekimoto et al. 2007; Matsuzaki et al. 2007, 2009; Murata et al. 2009; Nagata et al. 2009; Alarcón et al. 2009; Kawamata et al. 2011; Fig. 2c). Linker phosphorylation can modify $\mathrm{COOH}-$ terminally phosphorylated R-Smad signaling (Kretzschmar et al. 1999; Mori et al. 2004; Matsuura et al. 2004; Ho et al. 2005; Sekimoto et al. 2007; Matsuzaki et al. 2009). Differential localization of kinases and phosphatases in the cytoplasm or nucleus raises the intriguing possibility of different temporal dynamics for cytoplasmic or nuclear 
Fig. 2 Three Smad

phosphoisoform types:

$\mathrm{pSmad} 2 \mathrm{C}$ and $\mathrm{pSmad} 3 \mathrm{C}$

pSmad2L and pSmad3L, and $\mathrm{pSmad} 2 \mathrm{~L} / \mathrm{C}$ and $\mathrm{pSmad} 3 \mathrm{~L} / \mathrm{C}$. a The canonical TGF- $\beta$ signaling pathways. Following phosphorylation $(P)$ on their carboxyl termini by TGF- $\beta$ type I receptor $(T \beta R I)$, Smad2 and Smad3 partner with the common mediator Smad4 translocate to the nucleus. Not only TNF- $\alpha$, but also TGF- $\beta$ activates c-Jun $\mathrm{N}$-terminal kinase $(J N K)$ and p38 mitogen-activated protein kinase $(M A P K)$ through mitogen-activated kinase kinase 4/7 (MKK4/7) and $M K K 3 / 6$ activated by TGF- $\beta$ activated kinase 1 (TAK1). JNK and p38 MAPK phosphorylate other transcription factors, such as c-Jun and activating transcription factor $2(A T F-2)$, that cooperate with nuclear Smads in mediating TGF- $\beta$ induced transcriptional responses ( $S B E$ Smad-binding element, $T B E$ transcription factor binding element). b Representation of phosphorylation sites in Smad2 and Smad3. Catalytically active T $\beta$ RI and Activin type I receptor (ActRI) phosphorylate $\mathrm{COOH}$-tail serine residues. JNK and cyclin-dependent kinase $(C D K)$ alternatively phosphorylate Smad2/3 at specific sites in their middle linker regions. c $\mathrm{T} \beta \mathrm{RI} / \mathrm{ActRI}$ and JNK/CDK differentially phosphorylate Smad2/3 to create three phosphorylated forms (phosphoisoforms): $\mathrm{COOH}$-terminally phosphorylated Smad2/3 (pSmad2C and pSmad $3 C$ ), linker phosphorylated Smad2/3 (pSmad $2 L$ and $p \operatorname{Smad} 3 L$ ), and dually phosphorylated $S m a d 2 / 3$ ( $p S m a d 2 L / C$ and $p S m a d 3 L / C$ ).

Cytoplasmic localization is seen for pSmad2L, whereas the other phosphoisoforms localize to the cell nuclei a
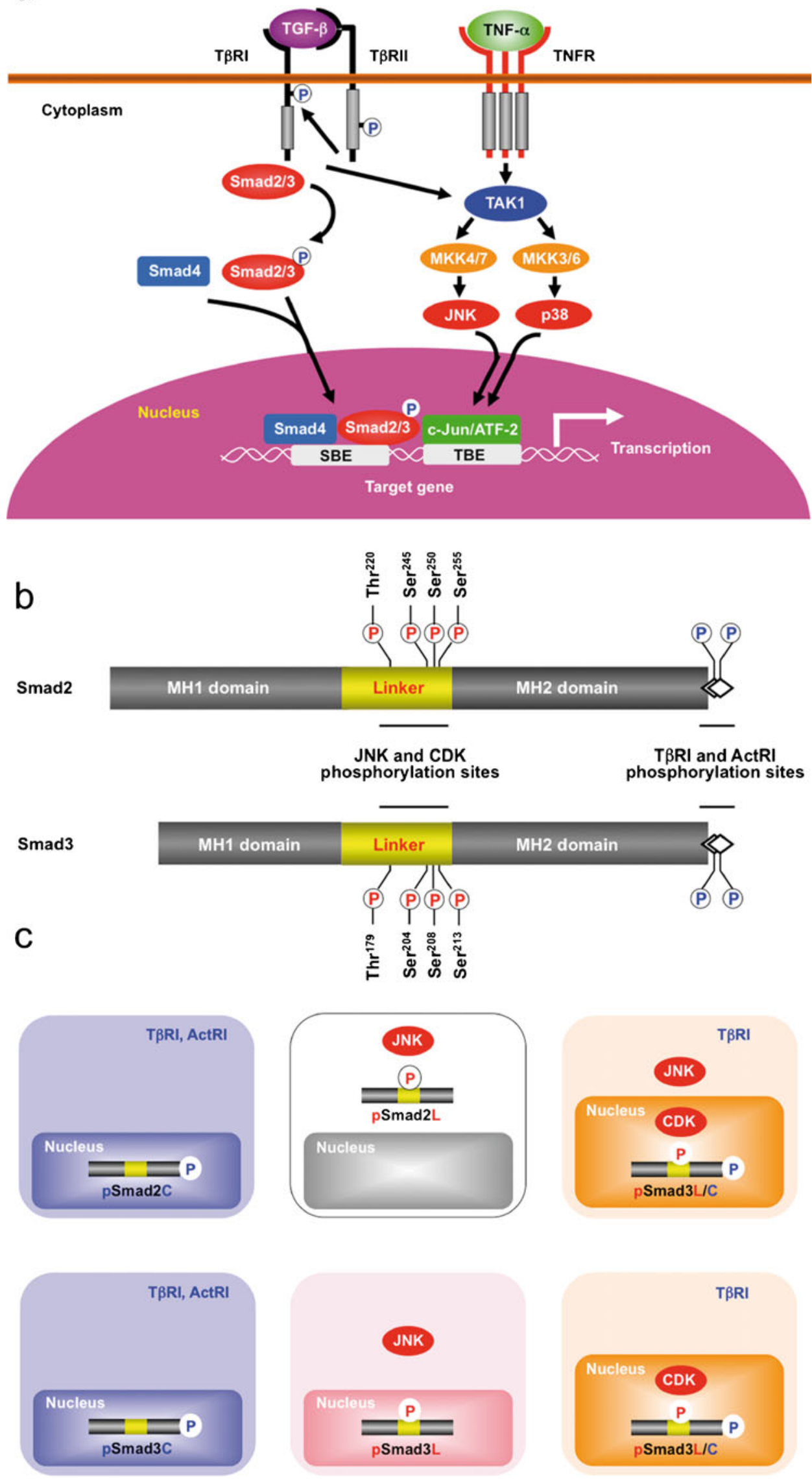
R-Smad phosphoisoforms and adds to the repertoire of signaling responses that determine cell-fate decisions (another related review, manuscript in preparation). Immunohistochemical and immunofluorescence analyses with specific Abs in human tissues can be used to examine the clinical significance of context-dependent and cell-type-specific signaling mediated by R-Smad phosphoisoforms, by the comparison of the tissue/ cellular localization of these phosphoisoforms in various pathologic specimens.

\section{Cytostatic TGF- $\beta$ /activin signaling: involvement of the pSmad3C pathway}

Both TGF- $\beta$ and activin inhibit the proliferation of normal hepatocytes, thus being crucial for hepatic homeostasis (Fausto et al. 2006). In the context of cell cycle control, the most important targets of action by TGF- $\beta$ /activin are the genes encoding two CDK inhibitors ( $221^{\text {WAFI }}$ and $p 15^{I N K 4 B}$ ) and $c$-Myc (Massagué 2008). The pSmad3C signal induces the expression of these CDK inhibitors and represses the expression of c-Myc, shutting down cell cycle progression in the early/mid- $\mathrm{G}_{1}$ phase of the cell cycle (Fig. 3a). Development of HCC is ordinarily blocked through the actions of the pSmad3C pathway, which can cause normal hepatocytes to cease growth and enter apoptosis after hepatocytic proliferation, in part through the ability of $\mathrm{pSmad} 3 \mathrm{C}$ to induce or repress the expression of various apoptosis-associated proteins such as Bcl2 (Yang et al. 2006).

\section{Mitogenic JNK signaling: involvement of the pSmad3L pathway}

Pro-inflammatory cytokines strongly activate the JNK pathway, whereas TGF- $\beta$ /activin activates it more weakly

Fig. 3 Reversible shifting of Smad3-dependent signaling between hepatocytic growth and inhibition indicates that pSmad3C transmits a cytostatic TGF- $\beta$ /activin signal, whereas pro-inflammatory cytokines transmit a mitogenic signal through the JNK-dependent pSmad3L pathway. a TGF- $\beta$ or activin treatment activates T $\beta$ RI or ActRI, further leading to the direct phosphorylation of Smad3C. pSmad3C inhibits hepatocyte growth by up-regulating $\mathrm{p} 21^{\mathrm{WAF} 1}$ transcription. b Although TGF- $\beta$ and the activin signal weakly phosphorylate Smad3L in normal hepatocytes (dotted arrow), pro-inflammatory cytokines can transmit a mitogenic signal through the JNK-dependent pSmad3L pathway to participate in hepatocytic growth, possibly by stimulating the transcription of the $c-M y c$ gene. Linker phosphorylation of Smad3 indirectly prevents its $\mathrm{COOH}$-tail phosphorylation (yellow star), pSmad3C-mediated $\mathrm{p} 21^{\mathrm{WAF} 1}$ transcription, and consequently the cytostatic effect of TGF- $\beta$ / activin upon normal hepatocytes. $\mathbf{c}$ Either various JNK inhibitors or a Smad3 mutant lacking the JNK phosphorylation sites in the linker region can eliminate mitogenic pSmad3L signaling and restore the lost cytostatic pSmad3C signaling observed in mature hepatocytes

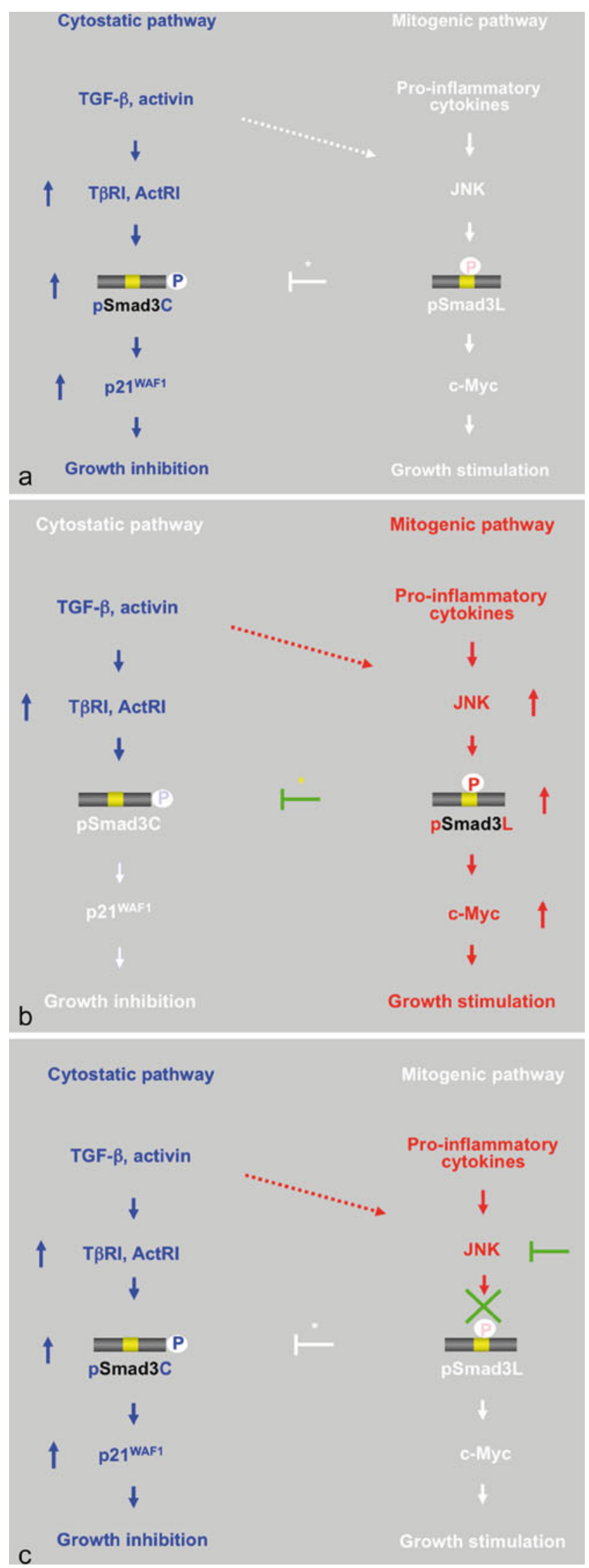


(Derynck and Zhang 2003; Fig. 3b). Ras/MAPK signaling has previously been shown to induce the phosphorylation of Smad2 and Smad3 at their linker regions (Kretzschmar et al. 1999). Smad2 phosphorylation at the linker region inhibits the nuclear accumulation of Smad2 without interfering with the TGF- $\beta$-induced phosphorylation of its $\mathrm{COOH}$-tail (de Caestecker et al. 1998; Lehmann et al. 2000; Yue and Mulder 2000; Oft et al. 2002; Funaba et al. 2002; Janda et al. 2002; Suzuki et al. 2007; Matsuzaki et al. 2009; Li et al. 2009; Burch et al. 2010; Jiang et al. 2010). In contrast, linker phosphorylation does not retain Smad3 in the cytoplasm, permitting further consequences of the Ras/MAPK signaling. The mechanisms underlying this difference between the two R-Smads are not known, but the phosphorylation sites of Smad3 at clusters of three serine residues in its linker region $\left(\mathrm{Ser}^{204}, \mathrm{Ser}^{208}\right.$, and $\left.\mathrm{Ser}^{213}\right)$ are different in sequence from the corresponding linker phosphorylation sites $\left(\mathrm{Ser}^{245}, \mathrm{Ser}^{250}\right.$, and $\mathrm{Ser}^{255}$ ) of Smad2 (Fig. 1b).

Several lines of evidence indicate that JNK transmits a mitogenic signal via the pSmad3L pathway (Fig. 3b). First, pro-inflammatory cytokines induce Smad3 phosphorylation at its linker region (Matsuzaki et al. 2007; Kawamata et al. 2011). Second, JNK can directly phosphorylate the linker site in vitro, and JNK inhibitors block linker phosphorylation in vivo (Mori et al. 2004; Sekimoto et al. 2007). Third, mitogens translocate pSmad3L into the nucleus (Mori et al. 2004; Sekimoto et al. 2007; Matsuzaki et al. 2009). Fourth, nuclear pSmad3L forms a hetero-complex with Smad4 (Furukawa et al. 2003; Mori et al. 2004). Fifth, nuclear pSmad3L binds to the Smad-binding element in the promoter with high affinity and specificity (Furukawa et al. 2003; Wang et al. 2005; Prokova et al. 2005; Vasilaki et al. 2009). Finally, mitogens induce the growth of normal epithelial cells by up-regulating c-Myc, and such mitogenic effects are blocked by Smad3 mutants lacking linker phosphorylation sites and by JNK inhibitors (Sekimoto et al. 2007). These results strongly support the notion that JNK specifically signals through Smad3 (Engel et al. 1999).

\section{Reversibility of phospho-Smad3 signaling between epithelial cell growth and inhibition}

JNK-mediated pSmad $3 \mathrm{~L}$ and T $\beta R I / A c t R I-$ mediated $\mathrm{pSmad} 3 \mathrm{C}$ signals oppose each other; most importantly, the balance between cell growth and inhibition can shift (Fig. 3). Linker phosphorylation of Smad3 blocks $\mathrm{COOH}$-tail phosphorylation induced by T $\beta R I / a c t R I$ (Mori et al. 2004; Ho et al. 2005; Sekimoto et al. 2007; Murata et al. 2009; Nagata et al. 2009; Fig. 3b, star). Mitogenic signaling accelerates the nuclear transport of pSmad3L from the cytoplasm, while preventing Smad3C phosphorylation, pSmad3C-mediated transcription, and the anti-proliferative effects of TGF- $\beta$ /activin (Sekimoto et al. 2007). Smad3 mutants lacking linker phosphorylation sites, and JNK inhibitors, can restore growth inhibitory and transcriptional responses to TGF- $\beta$ /activin in Rastransformed cells and pre-neoplastic hepatocytes, both in vitro and in vivo (Sekimoto et al. 2007; Murata et al. 2009; Nagata et al. 2009; Fig. 3c). Our model implies that the JNK pathway directly or indirectly modulates pSmad3C- and pSmad3L-mediated signaling to regulate target genes, resulting in an antagonistic relationship between cell growth and inhibition. Thus, the effectiveness of cytostatic TGF- $\beta$ / activin signaling can depend on the extent of Smad3 phosphorylation at the linker region.

\section{Mesenchymal TGF- $\beta$ signaling: involvement of the $\mathrm{pSmad} 2 \mathrm{~L} / \mathrm{C}$ and $\mathrm{pSmad} 3 \mathrm{~L} / \mathrm{C}$ pathways}

Recent clarification of the molecular aspects of Smad phosphoisoform signaling further offers potential for understanding the molecular mechanisms regulating growth inhibition versus stimulation by TGF- $\beta$ in fibroblasts. Only Rb family members were originally known to be substrates of CDK4, until the Liu group reported that Smad3 is phosphorylated by both CDK4 and CDK2 in vivo and in vitro (Matsuura et al. 2004). CDK4-mediated phosphorylation of Smad3 at its linker region inhibits its transcriptional activity and the anti-proliferative activity of TGF- $\beta$ in fibroblasts (Matsuura et al. 2004; Wang et al. 2009). Importantly, COOH-tail phosphorylation of Smad3 is necessary for TGF- $\beta$-induced phosphorylation of Smad 3 at its linker region in fibroblasts (Wang et al. 2009; Matsuura et al. 2010). Consistent with these observations concerning Smad3, we have confirmed that the nuclear cyclin D1.CDK4 complex of fibroblasts activated by TGF- $\beta$, pro-inflammatory cytokines, and platelet-derived growth factor (PDGF) signaling directly phosphorylates the linker segment of pSmad2C to produce pSmad2L/C (Matsuzaki et al. 2009; unpublished data). Other nuclear CDK members including CDK8 and CDK9 phosphorylate the linker portions of pSmad1C, pSmad2C, and $\mathrm{pSmad} 3 \mathrm{C}$ to create $\mathrm{pR}-\mathrm{SmadL} / \mathrm{C}$ (Alarcón et al. 2009). The expression of c-Myc in fibroblasts is initially repressed by TGF- $\beta$, but subsequent cyclin D1.CDK4 undergoes a complete functional change to stimulate c-Myc (Matsuzaki et al. 2009). In contrast, TGF- $\beta$ persistently inhibits c-Myc expression and growth in fibroblasts carrying $\operatorname{Smad} 2 / 3$ mutants lacking CDK4 phosphorylation sites in their linker regions (Fig. $2 b$ ). Collectively, TGF- $\beta$ inhibits cell growth by down-regulating the c-Myc oncoprotein via the pSmad2C and pSmad3C pathways (Fig. 4a, left). However, signaling activated by TGF- $\beta$, pro-inflammatory cytokines, and PDGF can enhance fibroblast growth by up-regulating c-Myc via the CDK4-dependent $\mathrm{pSmad} 2 \mathrm{~L} / \mathrm{C}$ and $\mathrm{pSmad} 3 \mathrm{~L} / \mathrm{C}$ pathways in cell nuclei (Fig. 4a, right). 
Fig. 4 Spatial and temporal dynamics of R-Smad phosphoisoforms differing between HSC and MFB. a Phospho-Smad signaling in HSC: involvement of $\mathrm{pSmad} 2 \mathrm{~L} / \mathrm{C}$ and $\mathrm{pSmad} 3 \mathrm{~L} / \mathrm{C}$ pathways. TGF- $\beta$ inhibits HSC growth by down-regulating c-Myc oncoprotein via the $\mathrm{pSmad} 2 \mathrm{C}$ and $\mathrm{pSmad} 3 \mathrm{C}$ pathways (left); TGF- $\beta$, TNF- $\alpha$, and PDGF, in turn, enhance HSC growth and collagen synthesis by up-regulating the transcription of c-Myc and collagen via the $\mathrm{pSmad} 2 \mathrm{~L} / \mathrm{C}$ and $\mathrm{pSmad} 3 \mathrm{~L} / \mathrm{C}$ pathways (right).

b Phospho-Smad signaling in MFB: involvement of the mitogenic pSmad3L and the fibrogenic $\mathrm{pSmad} 2 \mathrm{~L} / \mathrm{C}$ pathways. TNF- $\alpha$ activates JNK, which phosphorylates Smad2L and Smad3L (left). After the COOH-tail phosphorylation of cytoplasmic pSmad2L by T $\beta$ RI, pSmad2L/C undergoes translocation to the nucleus, where it interacts with pSmad3L and Smad4. The Smad complex then stimulates plasminogen activator inhibitor-1 (PAI-1) transcription and ECM deposition (right)

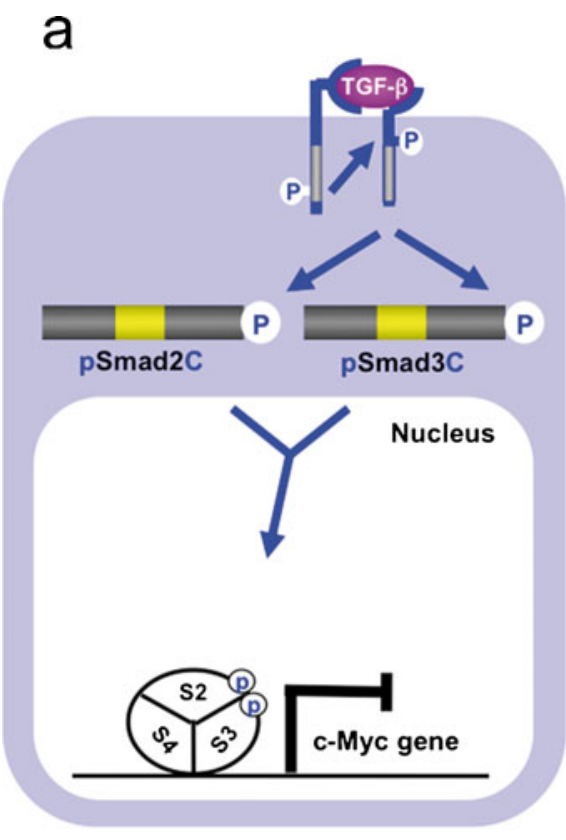

Growth inhibition

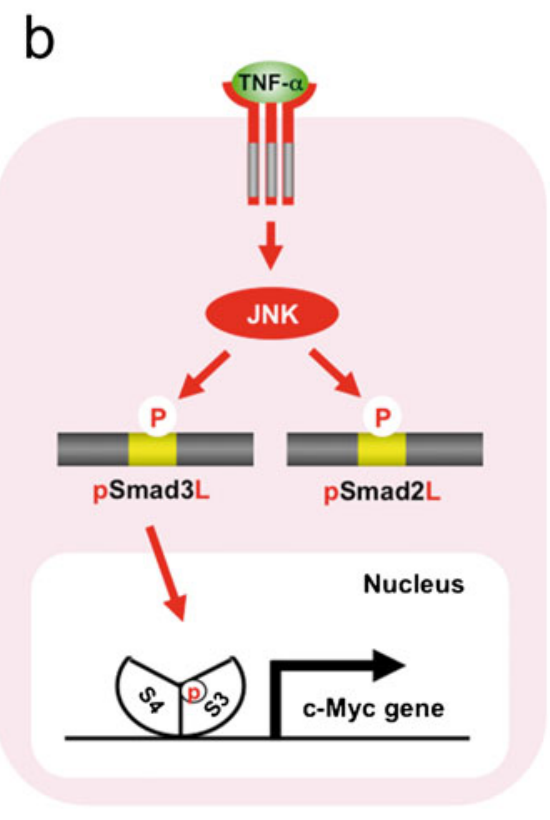

Growth stimulation

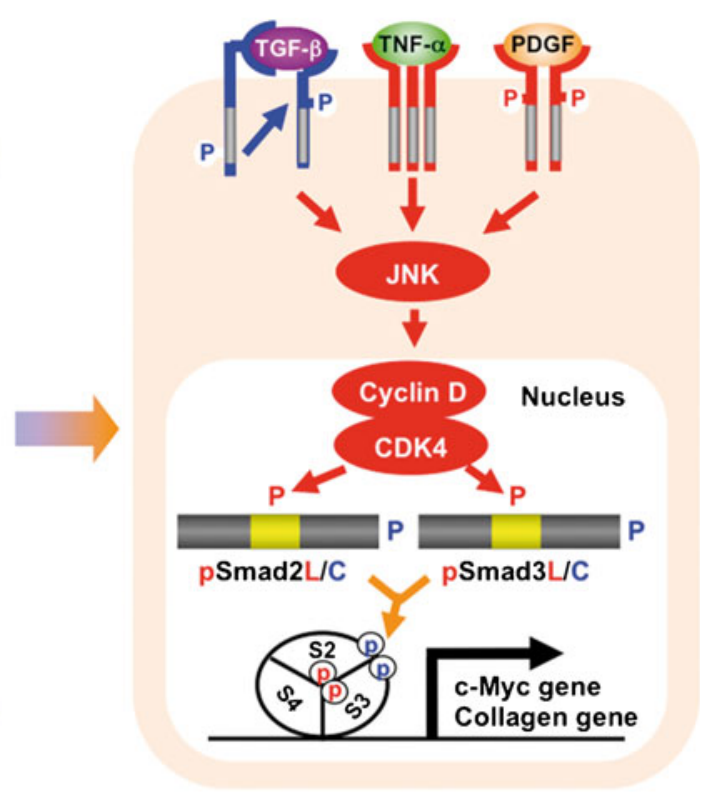

Collagen synthesis

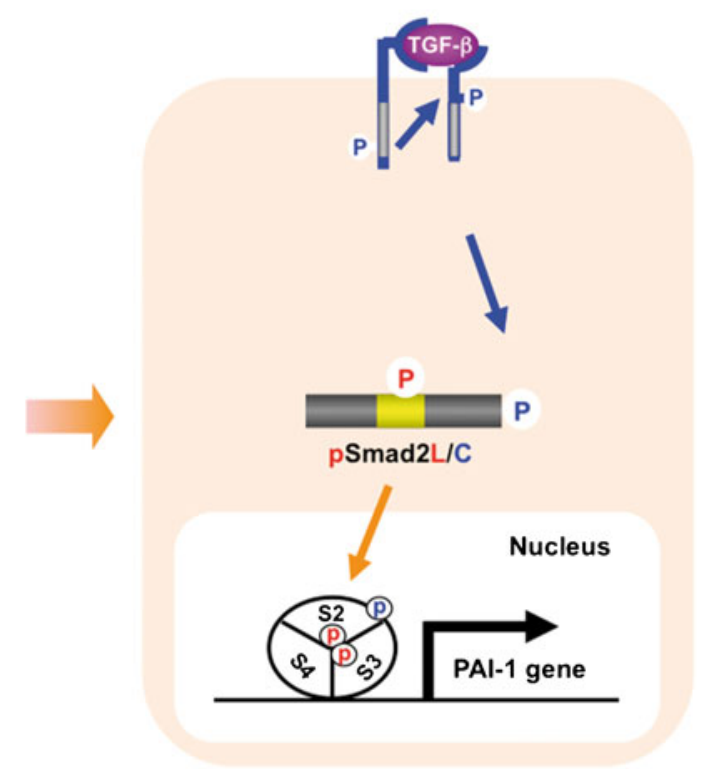

ECM deposition
Several soluble factors, including cytokines, growth factors, chemokines, and oxidative stress products, play a role in the activation of HSC (Friedman 2010). Among cytokines, TGF- $\beta$ is the most potent stimulus for the production of collagen by activated HSC (Inagaki and Okazaki 2007; Kisseleva and Brenner 2008). Proinflammatory cytokines such as TNF- $\alpha$, IL-1 $\beta$, and IL-6 are not only mitogenic, but also pro-fibrotic (Kisseleva and Brenner 2008; Grivennikov et al. 2010). PDGF acts as a potent mitogen for HSC via the Ras pathway and is involved in tissue repair after liver damage (Pinzani and Macias-Barragan 2010). Collagen synthesis by mesenchymal cells including fibroblasts, mesangial cells, and HSC appears to be promoted by $\mathrm{pSmad} 2 \mathrm{~L} / \mathrm{C}$ and $\mathrm{pSmad} 3 \mathrm{~L} / \mathrm{C}$. Li et al. (2009) have reported that ERK2 enhances the TGF- $\beta_{1}$-induced synthesis of type I and III collagen in fibroblasts, accompanied by Smad2 phosphorylation at linker sites. Ablation of ERK2 significantly down-regulates the synthesis of collagen I and III. In support of this finding, Jiang et al. (2010) have recently reported that $\mathrm{pSmad} 2 \mathrm{~L} / \mathrm{C}$ induced by both $\mathrm{T} \beta \mathrm{RI}$ and Erk/ 
JNK enhances the synthesis of collagen IV in rat mesangial cells. On the other hand, Hayashida et al. (2003) have found that the ERK-dependent phosphorylation of Smad3L increases collagen I synthesis by human mesangial cells in response to TGF- $\beta$. Moreover, we have shown that the co-treatment of primary cultured HSC with TGF- $\beta$ and PDGF enhances the transcription of the collagen $I$ gene via the pSmad3L/C pathway (Furukawa et al. 2003; Yoshida et al. 2005).

\section{Fibrogenic pSmad2L/C together with mitogenic pSmad3L pathways characterize TGF- $\beta$ signaling in myofibroblasts}

Hepatic fibrosis is characterized by the accumulation of excess ECM proteins, regardless of the underlying etiology. The amount of matrix deposition reflects a balance between its synthesis and degradation (Arthur 2000; Popov and Schuppan 2009). When the synthesis of ECM exceeds its degradation, the pathologic accumulation of ECM leads to liver fibrosis. The reversibility of experimental hepatic fibrosis and the striking decrease in collagenolytic activity observed in liver fibrosis models suggest the crucial importance of impaired matrix degradation in hepatic fibrogenesis (Pinzani and Macias-Barragan 2010). The plasminogen activator/plasmin system, which is situated upstream of the fibrolysis system, can directly degrade matrix component and indirectly inhibit ECM deposition (Eddy 2009). Plasminogen activator inhibitor-1 (PAI-1), the major physiologic inhibitor of plasminogen activator, is a potent promoter of fibrosis (Ha et al. 2009). PAI-1 also has a role in migration and invasion for various mesenchymal cells (Kwaan and McMahon 2009).

Methods of obtaining HSC from livers are now standardized (Kawada 1997), and the prolonged culture of HSC on plastic is widely accepted as a model of liver fibrosis (Friedman 2010). HSC spontaneously transdifferentiate to a myofibroblast (MFB) phenotype on plastic dishes, and this response recapitulates the features of activation in vivo. MFB usually retain the fibrogenic TGF- $\beta$ signaling component but have lost the capacity to respond to TGF- $\beta$ with growth arrest (Inagaki and Okazaki 2007). Such a state of altered TGF- $\beta$ responsiveness is also observed in Ras-transformed cells, which typically exhibit a limited growth inhibitory response to TGF- $\beta$, instead responding to TGF- $\beta$ with invasive and metastatic behavior (Oft et al. 1996, 2002).

A clue to the molecular mechanisms underlying this change is suggested by the differential cellular localization of pSmad2L and pSmad3L observed in both MFB and Rastransformed cells (Fig. 2c). JNK activated by either proinflammatory cytokines or hyperactive Ras stimulates the retention of most Smad2 protein in the cytoplasm
(Kretzschmar et al. 1999; Sekimoto et al. 2007) but facilitates the nuclear accumulation of pSmad3L (Furukawa et al. 2003; Sekimoto et al. 2007; Matsuzaki et al. 2007, 2009; Kawamata et al. 2011), while inhibiting tumorsuppressive pSmad3C signaling (Fig. 3b, left). Smad2 can accumulate in the nucleus only if its $\mathrm{C}$-terminus is phosphorylated under conditions of sustained linker phosphorylation by JNK. After COOH-tail phosphorylation of cytoplasmic pSmad2L by T $\beta R I, p S m a d 2 L / C$ undergoes translocation to the nucleus where it binds to the pSmad3L and Smad4 complex (Furukawa et al. 2003; Matsuzaki et al. 2009; Fig. 4b, right), which then in turn stimulates PAI-1 transcription (Furukawa et al. 2003). Promotion of PAI-1 expression and cellular invasion requires both complete linker and $\mathrm{COOH}$-tail phosphorylation of Smad2, indicating that TGF- $\beta$ induces the deposition of ECM and invasion via the pSmad2L/C pathway (Furukawa et al. 2003; Matsuzaki et al. 2009). As a result, MFB lose growth-inhibitory responsiveness to TGF- $\beta$, while TGF- $\beta$ can accelerate ECM accumulation and invasion.

\section{Phospho-Smad signaling in hepatocytes after acute liver injury: mitogenic pSmad3L signaling followed by cytostatic pSmad3C signaling}

A unique feature of adult mammalian liver is its ability to regenerate accurately lost mass, which occurs following surgical resection or diffuse liver injury (Michalopoulos 2007). Although the precise identity of the cytokines and the molecular mechanisms involved in liver regeneration are largely unknown, activin A appears to be a likely negative regulator of hepatocytic growth in static situations (Yasuda et al. 1993). Both activin A and its receptors are expressed in quiescent hepatocytes, and activin A inhibits the initiation of mitogen-induced DNA synthesis in hepatocytes (Date et al. 2000a). Blocking of the action of activin $\mathrm{A}$ by the addition of the activin antagonist follistatin or transfection with the follistatin gene or a dominantnegative activin receptor gene initiates DNA synthesis in normal liver and thereby increases liver volume (Kogure et al. 1995). In addition, quiescent hepatocytes show evidence of persistent phosphorylation of Smad3 at its C-terminus (Matsuzaki et al. 2007; Murata et al. 2009; Nagata et al. 2009; Fig. 5a, upper left).

Hepatocytes initiate the transition from the resting to the proliferative state after acute liver injury and partial hepatectomy (Michalopoulos 2007). Loss of parenchyma rapidly induces a wave of hepatocytic proliferation to restore the total mass of the liver to normal. Several converging lines of evidence have established that proinflammatory cytokines such as TNF- $\alpha$ and IL-6 are important components of the mitogenic pathways leading 
Fig. 5 Smad phosphoisoformmediated signals showing similarities and differences between hepatocytes and HSC in acute and chronic liver injuries. a (top row) Quiescent hepatocytes show persistent phosphorylation of Smad3 at its C-terminus by ActRI. After acute liver injury, the TGF- $\beta$-mediated pSmad $3 \mathrm{C}$ signaling terminates hepatocytic proliferation induced by the TNF- $\alpha$-mediated mitogenic pSmad3L pathway. b (top row) After acute liver injury, TGF- $\beta$ and TNF- $\alpha$ synergistically enhance the collagen synthesis of activated HSC via the $\mathrm{pSmad} 2 \mathrm{~L} / \mathrm{C}$ and $\mathrm{pSmad} 3 \mathrm{~L} / \mathrm{C}$ pathways. During the progression of chronic liver diseases, pre-neoplastic hepatocytes (a bottom row) persistently affected by TGF- $\beta$ together with TNF- $\alpha$ start to exhibit the same oncogenic (mitogenic) pSmad3L and fibrogenic $\mathrm{pSmad} 2 \mathrm{~L} / \mathrm{C}$ signaling as MFB (b, bottom row), thereby accelerating liver fibrosis and increasing the risk of hepatocellular carcinoma a

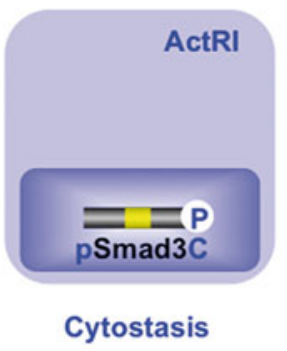

Acute liver injury (regenerative hepatocytes)

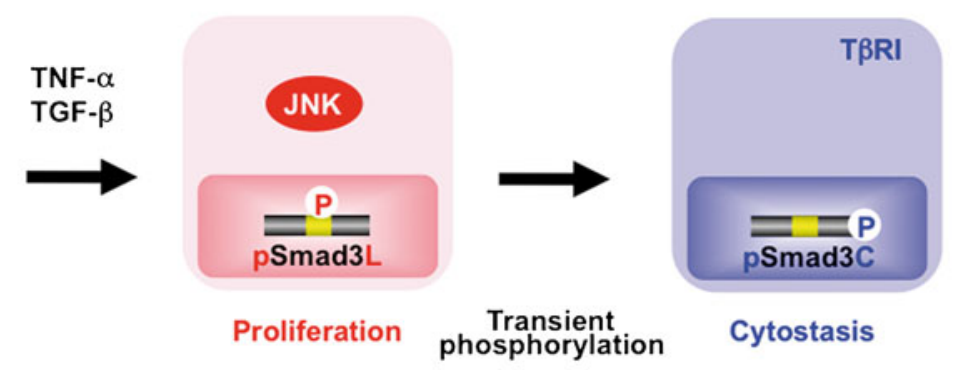

Chronic liver injury (pre-neoplastic hepatocytes)

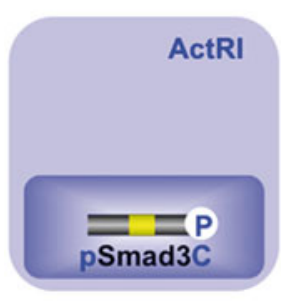

Cytostasis

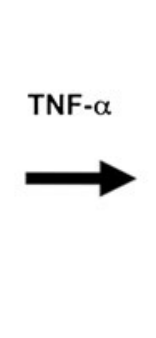

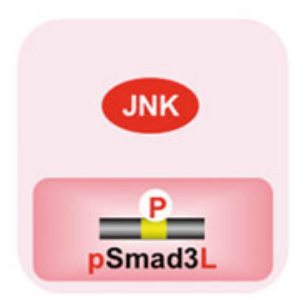

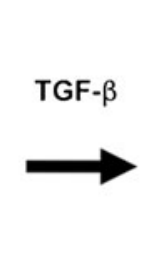

Carcinogenesis

Constitutive phosphorylation

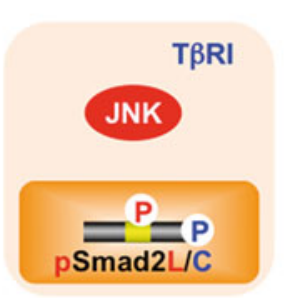

Fibrogenesis b

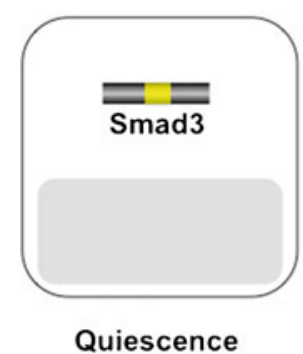

Quiescence
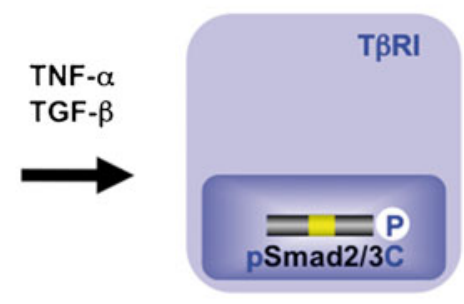

Cytostasis
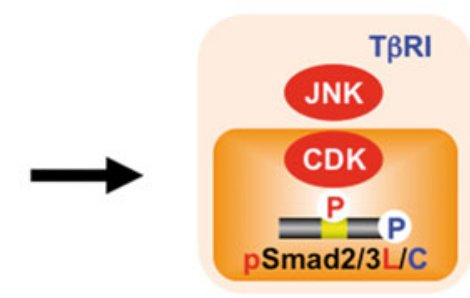

Tissue repair
Chronic liver injury (MFB)

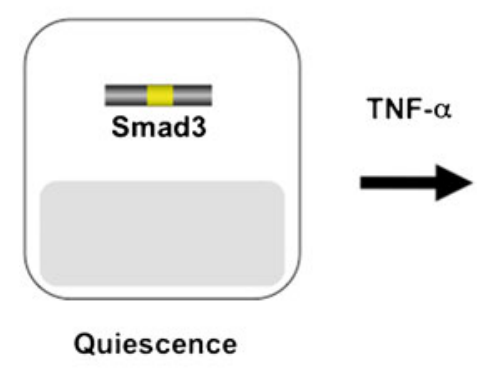

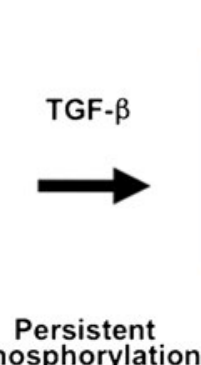

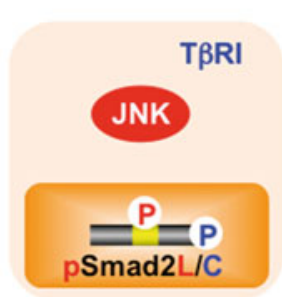

Fibrogenesis to regeneration after acute liver injury (Grivennikov et al. 2010). Treatment of hepatocytes with antibodies against TNF- $\alpha$ results in decreased DNA synthesis and JNK activity (Fausto et al. 2006). DNA synthesis during liver regeneration is severely impaired in mice with $\mathrm{TNF}-\alpha$ type I receptor deficiency (Yamada et al. 1997). After acute liver injury, however, both TGF- $\beta$ and activin A increase in the damaged livers within a time frame similar to that of pro- 
inflammatory cytokine increases (Tilg et al. 2006; Date et al. 1998, 2000a). This raises the problem as to how hepatocytes manage to proliferate in response to the mitogenic proinflammatory cytokine signal, despite elevated TGF- $\beta$ and activin concentrations. During liver regeneration, hepatocytes acquire temporary resistance to TGF- $\beta$ and activin A, allowing them to proliferate (Date et al. 1998, 2000a, 2000b). The phosphorylation pattern of Smad3 in regenerative hepatocytes after acute liver injury suggests an important participation of phospho-Smad3 in hepatocytic growth regulation. In actively growing hepatocytes, the intracellular phosphorylation at Smad3L is increased (Matsuzaki et al. 2007; Murata et al. 2009; Nagata et al. 2009; Fig. 5a, top middle). Translocated to the nucleus, inflammatory cytokine-induced pSmad3L stimulates c-Myc transcription (Matsuzaki et al. 2007; Nagata et al. 2009; Kawamata et al. 2011), which increases the proliferation of hepatocytes and opposes the cytostatic action of the $\mathrm{pSmad} 3 \mathrm{C} / \mathrm{p} 21^{\mathrm{WAF} 1}$ pathway (Fig. 3b). Accordingly, pSmad3C/p21 WAF1 is undetectable in regenerative hepatocytic nuclei; an escape from TGF- $\beta$ /activin-induced cytostasis is crucial in a subset of progenitor cells devoted to ensuring epithelial renewal. Thus, a shift from cytostatic pSmad3C to mitogenic pSmad3L signaling can permit liver regeneration in response to mitogenic pro-inflammatory cytokines, even though TGF- $\beta$ and activin concentrations are elevated after acute liver injury.

Liver regeneration is tightly controlled by a delicate balance between hepatocytic growth and inhibition. Antimitotic effects of TGF- $\beta$ contribute to the termination of hepatocyte proliferation observed following the wave of DNA synthesis in the regenerating liver. A return of TGF- $\beta$ sensitivity at later stages may limit hepatocyte proliferation and terminate liver regeneration (Date et al. 1998, 2000b). After a TNF- $\alpha$ and pSmad3L decrease, hepatocytic proliferation ceases, as decreases in pSmad3L can increase sensitivity to phosphorylation at Smad3C by $\mathrm{T} \beta \mathrm{RI}$ (Figs. 3c, 5a, top right). TGF- $\beta$-dependent pSmad3C appears to limit the proliferative response of regenerating hepatocytes through the inhibition of the G1-to-S phase cell-cycle transition.

\section{Phospho-Smad signaling in HSC after acute liver injury: involvement of the pSmad2 $\mathrm{L} / \mathrm{C}$ and $\mathrm{pSmad} 3 \mathrm{~L} / \mathrm{C}$ pathways}

After acute liver damage, HSC acquire an activated phenotype associated with gradual loss in retinoid content, which enhances cell proliferation/invasion and synthesis of large amounts of ECM components, particularly various types of collagens. How does cytostatic TGF- $\beta$ signaling in HSC take on collagen-producing features within inflammatory microenvironments during acute liver injury? To answer this question, we have focused on the Smad pathway, investigating the localization of $\mathrm{pSmad} 2 \mathrm{~L} / \mathrm{C}$ and $\mathrm{pSmad} 3 \mathrm{~L} / \mathrm{C}$ in chemically injured rat livers. These phosphoisoforms are involved in collagen synthesis and transmit a proliferative invasive TGF- $\beta$ signal in mesenchymal cells (Fig. 4a). Nuclear localization of $\mathrm{pSmad} 2 \mathrm{~L} / \mathrm{C}$ and $\mathrm{pSmad} 3 \mathrm{~L} / \mathrm{C}$ is seen in the activated HSC (Yoshida et al. 2005; Fig. 5b, top right). In particular, strong Smad2/3 phosphorylation at the $\mathrm{COOH}$-tail and threonine residues in the linker regions (Fig. 2b) is observed in the activated HSC (Yoshida et al. 2005; unpublished data). Because TGF- $\beta$, pro-inflammatory cytokines, and PDGF activate CDK4 via the JNK pathway in HSC (Reeves et al. 2000: Yoshida et al. 2005; Zhang et al. 2005; Kluwe et al. 2010; Fig. 4a), pro-inflammatory cytokines and PDGF can convert a cytostatic TGF- $\beta$ signal into a collagen-producing character in activated HSC under the influence of inflammatory microenvironments. Collectively, $\mathrm{pSmad} 2 \mathrm{~L} / \mathrm{C}$ and $\mathrm{pSmad} 3 \mathrm{~L} / \mathrm{C}$ signaling might mobilize HSC from the space of Disse to sites of damage, where the activated HSC contribute to tissue repair by producing large amounts of collagens (Fig. 5b, top right).

\section{Spatial and temporal dynamics of R-Smad phosphoisoforms: differences between epithelial and mesenchymal cells}

In contrast to the presence of the $\mathrm{COOH}$-tail phosphorylation of R-Smad in almost all cell types and tissues, the timing, duration, extent, and functional implications of linker phosphorylation depend on the cell type and context. Therefore, the influence of linker phosphorylation on COOH-tail phosphorylation has been an unsettled subject with various data suggesting that mitogen-mediated linker phosphorylation either inhibits (Kretzschmar et al. 1999; Engel et al. 1999; Wicks et al. 2000; Grimm and Gurdon 2002; Mori et al. 2004; Ho et al. 2005; Javelaud and Mauviel 2005; Sekimoto et al. 2007; Arany et al. 2008; Hamajima et al. 2009; Millet et al. 2009; Lin et al. 2010; Hong et al. 2010) or enhances (Brown et al. 1997; de Caestecker et al. 1998; Oft et al. 2002; Funaba et al. 2002; Hayashida et al. 2003; Furukawa et al. 2003; Matsuura et al. 2004; Yoshida et al. 2005; Kamaraju and Roberts 2005; Yang et al. 2008; Wang et al. 2009; Matsuzaki et al. 2009; Alarcón et al. 2009; He et al. 2010; Matsuura et al. 2010; Sasseville et al. 2010; Rachakonda et al. 2010; Jiang et al. 2010; Burch et al. 2010; van der Velden et al. 2011) events downstream of T $\beta R I$. Possible explanations exist for these different outcomes.

An involvement of the various mitogen-associated kinases might explain outcomes differing among various cell types and contexts. Normal epithelial cells show rapid phosphorylation at the linker regions in response to various mitogens, and the responsible kinases appear to act before 
R-Smad reaches the nucleus (Figs. 3, 5a, top). JNK is localized in the cytoplasm and directly phosphorylates the linker regions, creating pSmad2L and pSmad3L (Mori et al. 2004; Sekimoto et al. 2007). In contrast, mesenchymal cells show phosphorylation of R-Smad at their linker regions, and their kinases act after nuclear translocation of pSmad2C and pSmad3C in response to TGF- $\beta$ (Wang et al. 2009; Matsuzaki et al. 2009; Alarcón et al. 2009; Matsuura et al. 2010; Figs. 4a, 5b, top). Localized in the nucleus, CDKs directly phosphorylate the linker regions of pSmad2C and $\mathrm{pSmad} 3 \mathrm{C}$, producing $\mathrm{pSmad} 2 \mathrm{~L} / \mathrm{C}$ and $\mathrm{pSmad} 3 \mathrm{~L} / \mathrm{C}$ (Matsuura et al. 2004, 2010; Matsuzaki et al. 2009; Alarcón et al. 2009).

TGF- $\beta$ and mitogens exert mutually antagonistic effects on cell-cycle control and apoptosis in normal epithelial cells (Moses et al. 1990; Figs. 3, 5a, top). The mitogen drastically alters Smad3 signaling via the JNK pathway, increasing basal nuclear pSmad3L activity while shutting down TGF- $\beta$-dependent $\mathrm{pSmad} 3 \mathrm{C}$ that otherwise would be available to act in the nuclei of normal epithelial cells. Because migogenic pSmad3L signaling is followed by cytostatic pSmad3C signaling during normal epithelial regeneration, $\mathrm{pSmad} 2 \mathrm{~L} / \mathrm{C}$ and $\mathrm{pSmad} 3 \mathrm{~L} / \mathrm{C}$ rarely exist in normal epithelial cells either in vitro or in vivo (Figs. 3, 5a, top). In contrast, TGF- $\beta$ and mitogenic signaling synergistically promote the growth and invasion of mesenchymal cells (Matsuzaki et al. 2009; Matsuura et al. 2010). Blocking of either linker or $\mathrm{COOH}$-tail phosphorylation of Smad2 abrogates the synergistic responses of fibroblasts to TGF- $\beta$ and mitogens (Matsuzaki et al. 2009), indicating an involvement of $\mathrm{pSmad} 2 \mathrm{~L} / \mathrm{C}$ in this synergistic mesenchymal cell response (Figs. 4, 5b).

\section{Phospho-Smad signaling shared between pre-neoplastic hepatocytes and MFB during chronic liver injury: involvement of carcinogenic (mitogenic) pSmad3L and fibrogenic $\mathrm{pSmad} 2 \mathrm{~L} / \mathrm{C}$ pathways}

Current evidence suggests that the regulation of ECM accumulation in acute and chronic liver diseases involves various mechanisms, even though $\mathrm{HSC}$ are the principal effector in both cases (Friedman 2010). As a result of chronic liver damage, HSC undergo progressive activation to become MFB-like cells. During transdifferentiation in culture, pSmad3C-mediated signal decreases, whereas the pSmad3L pathway predominates (Furukawa et al. 2003; Fig. 4b, left). The observations fully support the finding of pSmad3L rather than $\mathrm{pSmad} 3 \mathrm{C}$ in the nuclei of $\alpha$-smooth muscle actin (SMA)-immunoreactive MFB in the portal tracts of chronically HCV-infected liver specimens (Matsuzaki et al. 2007; Fig. 5b, bottom middle). The presence of $\alpha$-SMA is associated with the transdifferentiation of HSC into scar-forming MFB, an event that is considered pivotal in the fibrogenic response (Pinzani and Macias-Barragan 2010).

Similarly to MFB, hepatocytes in $\mathrm{HCV}$-infected livers exhibit phosphorylation at Smad3L, particularly those adjacent to inflamed portal tracts (Matsuzaki et al. 2007; Fig. 5a, bottom middle). Thus, hepatocytes are regulated by the same pSmad3L pathway as are MFB. The extent of the phosphorylation at Smad3L is less in hepatocytes distant from portal tracts, in sharp contrast to pSmad3C, which is predominantly located in hepatocytic nuclei distant from portal tracts (Matsuzaki et al. 2007). TGF- $\beta$ and proinflammatory cytokines are released from infiltrating Kupffer cells in portal tracts to activate JNK (Yoshida et al. 2005; Kluwe et al. 2010). These findings, together with in vitro data (Fig. 3b), suggest that pro-inflammatory cytokine-dependent JNK can convert Smad3 to pSmad3L in both affected hepatocytes and MFB in chronic hepatitis (Fig. 5a, b, lower middle).

During the carcinogenic process, chronic inflammation drives carcinogenesis via a shift from the tumor-suppressive pSmad3C to the oncogenic pSmad3L pathway (Matsuzaki et al. 2007; Nagata et al. 2009). Many tumor-enhancing effects of pro-inflammatory cytokines on hepatocytes are exerted at the level of tumor promotion (Grivennikov et al. 2010). TNF- $\alpha$ promotes HCC occurrence in mice lacking the Pglycoprotein Mdr2 (Pikarsky et al. 2004). Cholestatic inflammation in these mice is followed by HCC. HCC incidence can be enhanced by another member of the TNF family, lymphotoxin $\beta$ (Haybaeck et al. 2009). Tumorpromoting cytokines produced by Kupffer cells activate several transcription factors such as nuclear factor kappa B, signal transducer and activator of transcription 3, and activator protein 1 in pre-malignant hepatocytes ( $\mathrm{He}$ and Karin 2011). The activated transcription factors stimulate the transcription of their target genes involved in hepatocytic proliferation and survival, which represents a major tumorpromoting mechanism. Similar to these transcription factors, the presence of hepatocytic Smad3 in human chronic liver diseases is rarely the result of direct mutations (Roberts et al. 2006). Instead, pSmad3L depends on mitogenic proinflammatory cytokine signals produced by neighboring Kupffer cells.

Pre-neoplastic hepatocytes and HCC show a reduction of anti-mitogenic responses to TGF- $\beta$ (Matsuzaki et al. 2000a, $2000 \mathrm{~b}$ ). Escaping the cytostatic action of pSmad3C is a critical step for progression to full malignancy in cancers, which must overcome multiple fail-safe genetic controls (Wakefield and Roberts 2002; Pardali and Moustakas 2007; Massague 2008). The TGF- $\beta / p S m a d 3 C$ pathway is required for the maintenance of genomic stability, induction of replicative senescence, and suppression of telomerase 
(Glick et al. 1996; Tremain et al. 2000; Yang et al. 2001). Selection for genetic instability occurs in clones of aberrant cells able to produce tumors, since genetic instability greatly accelerates the accumulation of further genetic and epigenetic changes required for tumor progression.

Evidence that fibrosis is reversible has intensified interest in the regulation of matrix degradation and fibrosis resolution. Data from transgenic mice that overexpress PAI-1 and from PAI-1-knockout mice support a role in vivo for PAI-1 in experimental fibrotic diseases (Eitzman et al. 1996). Moreover, the introduction of a PAI-1 small interfering RNA attenuates the deposition of ECM and hydroxyproline content in experimental hepatic fibrosis ( $\mathrm{Hu}$ et al. 2009). Plasma TGF- $\beta$, TNF- $\alpha$, and PAI- 1 concentrations are usually elevated in patients with chronic liver diseases (Shirai et al. 1994; Tilg et al. 2006; Sugano et al. 2003). How does TGF- $\beta$ signaling in hepatocytes and MFB acquire pro-fibrogenic properties under persistent inflammatory microenvironments during chronic liver injury? Since $\mathrm{pSmad} 2 \mathrm{~L} / \mathrm{C}$ transmits a fibrogenic signal by stimulating PAI-1 transcription (Fig. 4b, right), we have investigated the $\mathrm{pSmad} 2 \mathrm{~L} / \mathrm{C}$ pathway in human chronic liver disease. The results indicate the nuclear localization of $\mathrm{pSmad} 2 \mathrm{~L} / \mathrm{C}$ in PAI-1-immunoreactive MFB and hepatocytes in chronic hepatitis specimens (Tahashi et al. 2002; Furukawa et al. 2003; Matsuzaki et al. 2007; unpublished data). Various reports demonstrate transcriptional induction of the PAI-1 gene by TGF- $\beta$ and TNF- $\alpha$ (Nagamine 2008). Thus, TGF- $\beta$ and TNF- $\alpha$ can mediate pSmad2L/C signaling, which induces PAI-1 expression and promotes ECM deposition in hepatocytes and MFB, accelerating liver fibrosis (Fig. 5a, b, lower right).

We have recently proposed a colorectal cancer model of tumor growth and invasion that involves progressive increases in $\mathrm{pSmad} 2 \mathrm{~L} / \mathrm{C}$ and $\mathrm{pSmad} 3 \mathrm{~L}$, with the inhibition of tumorsuppressive pSmad3C signaling (Yamagata et al. 2005; Matsuzaki et al. 2009; Kawamata et al. 2011). Invasive $\mathrm{pSmad} 2 \mathrm{~L} / \mathrm{C}$ together with oncogenic $\mathrm{pSmad} 3 \mathrm{~L}$ can mediate pro-tumorigenic TGF- $\beta$ signaling, which allows carcinomas to acquire the invasive and proliferative properties needed for progression (another related review, manuscript in preparation). Malignant phenotypes can be induced by tumor microenvironments rather than by genetic changes within carcinomas (Weinberg 2007). Because benign colorectal tumors lack inflammatory microenvironments, these tumors do not show pro-inflammatory cytokine/TGF- $\beta$ dependence; rather, they develop into colorectal cancers independently of any fibrotic process. In contrast, hepatocytes in chronic hepatitis are strongly influenced by stromally produced pro-inflammatory cytokines, PDGF, and TGF- $\beta$ signals (Gotzmann et al. 2006), and pre-neoplastic hepatocytes affected by inflammatory microenvironments can show fibrogenic pSmad2L/C and oncogenic pSmad3L signaling (Fig. 5a, lower right). Consequently, human chronic hepatitis usually progresses to $\mathrm{HCC}$ in a process closely related to hepatic fibrosis.

Our model supports previous reports showing that hepatocytes promote fibrogenesis via a TGF- $\beta /$ Smad signal. Dooley et al. (2008) have reported that overexpression of the inhibitory Smad 7 in hepatocytes attenuates TGF- $\beta$-mediated fibrogenesis by blocking the Smad signal. Because the large latent TGF- $\beta$ complex, consisting of TGF- $\beta$, the N-terminal part of its precursor, and the latent TGF- $\beta$ binding protein, exists in not only HSC but also hepatocytes, it can transmit the pro-fibrogenic signal (Roth-Eichhorn et al. 1998), although the intracellular functions of the TGF- $\beta$ complex remain unknown. The TGF- $\beta$ down-stream mediator, connective tissue growth factor (CTGF), also involves hepatic fibro-carcinogenesis (Weng et al. 2007). CTGF expression increases in fibrotic livers and various tumor tissues (Gressner 2009). More importantly, in vivo knockdown of CTGF by small interfering RNA leads to the substantial attenuation of experimental liver fibrosis. Differential regulation of CTGF expression in hepatocytes and HSC by the Smad2 signal might contribute to hepatic fibro-carcinogenesis (Gressner et al. 2007). Interestingly, metylxanthine caffeine inhibits the synthesis of CTGF in hepatocytes and HSC, primarily by inducing the degradation of Smad2 (Gressner 2009).

\section{$\mathrm{JNK} / \mathrm{pSmad} 3 \mathrm{~L}$ pathway is an important target for therapy against emergence of $\mathrm{HCC}$}

Clinical analyses of pSmad3L and $\mathrm{pSmad} 3 \mathrm{C}$ in human tumor formation have provided substantial mechanistic insights. For example, specimens from patients with chronic hepatitis $\mathrm{C}$ who develop HCC show abundant Smad3L but limited Smad3C phosphorylation in hepatocytic nuclei, whereas other patients with abundant hepatocytic pSmad3C but limited pSmad3L do not develop HCC (Matsuzaki et al. 2007). During HCV-related hepatocarcinogenesis, JNK-activated chronic inflammation confers a selective advantage on preneoplastic hepatocytes by shifting Smad3 signaling from the tumor-suppressive pSmad3C to the oncogenic pSmad3L pathway, leading to HCC (Fig. 6). The same relationships are observed in human HBV-related hepatocarcinogenesis (Murata et al. 2009). These clinical observations support a role for pSmad3C as a tumor-suppressor and for pSmad3L as a promoter during human carcinogenesis.

The inhibition of TNF- $\alpha$ receptor and JNK by using genetic, pharmacologic, or antibody-mediated approaches abolishes human tumors in a tumor-cell-autonomous fashion, indicating that the TNF- $\alpha / \mathrm{JNK}$ cascade promotes 
Fig. 6 Reversible shifting of hepatocytic Smad3-dependent signaling between tumorsuppression and carcinogenesis. During the carcinogenic process in human chronic liver diseases, chronic inflammation drives carcinogenesis via a shift from the $\mathrm{pSmad} 3 \mathrm{C}$ to the $\mathrm{pSmad} 3 \mathrm{~L}$ pathway. Linker phosphorylation of Smad3 indirectly prevents Smad3C phosphorylation, pSmad3C-mediated transcription, and the cytostatic effect of TGF- $\beta$ / activin upon hepatocytes. Inhibition of JNK activity abolishes pSmad3L-mediated oncogenic signaling, while restoring the lost tumorsuppressive $\mathrm{pSmad} 3 \mathrm{C}$ signaling observed in normal hepatocytes
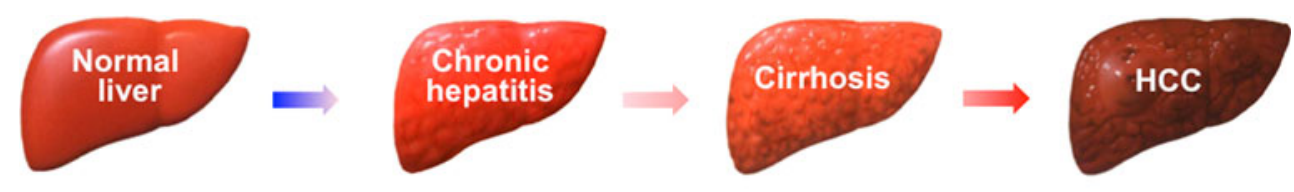

Tumor-suppressive pathway

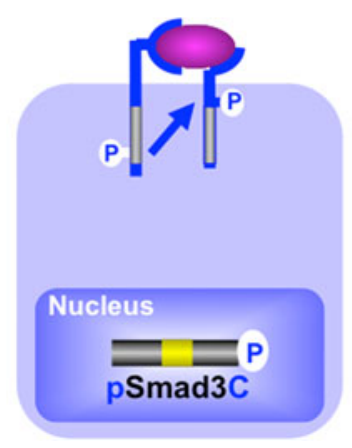

Carcinogenic pathway

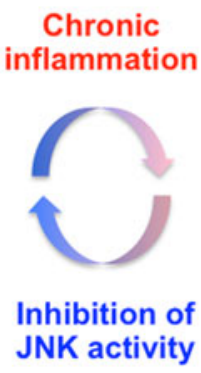

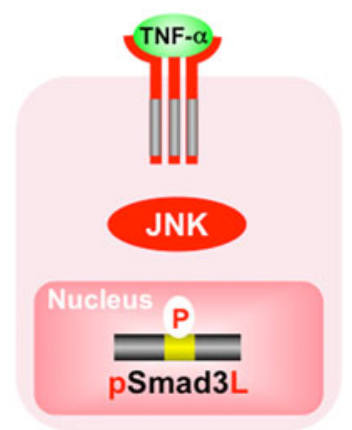

human neoplasia (Zhang et al. 2007). Since JNK acts as an important regulator of Smad3 signaling and increases the basal amount of hepatocytic pSmad3L available for cell growth while inactivating the TGF- $\beta$-dependent cytostatic actions of pSmad3C (Fig. 3), pharmacologic interference with $\mathrm{JNK} / \mathrm{pSmad} 3 \mathrm{~L}$ signaling might interrupt carcinogenesis. A key therapeutic aim in chronic liver disorders is the restoration of the lost tumor-suppressive function observed in normal hepatocytes, at the expense of effects promoting hepatic carcinogenesis (Felsher 2004). To accomplish this difficult aim, Nagata et al. (2009) administered a JNK inhibitor SP600125 into rats and were able to suppress chemical hepatocarcinogenesis by shifting hepatocytic Smad3 signaling from the oncogenic $\mathrm{pSmad} 3 \mathrm{~L}$ pathway to the tumor-suppressive pSmad3C pathway (Fig. 6). This study provides proof-of-principle that the $\mathrm{JNK} / \mathrm{pSmad} 3 \mathrm{~L}$ pathway is an important target for therapy devised to reduce the emergence of HCC in the context of chronic liver injury. We should also consider whether the long-term use of drugs inhibiting C-terminal phosphorylation of R-Smad might itself cause cancer development (Bellam and Pasche 2010).

\section{Concluding remarks and perspectives}

This review summarizes current information available concerning Smad phosphoisoform-mediated signals and shows the similarities and differences between epithelial and mesenchymal cells in acute and chronic liver injuries. After acute liver injury, TGF- $\beta$-mediated pSmad $3 \mathrm{C}$ signaling terminates the hepatocytic proliferation induced by the proinflammatory cytokine-mediated mitogenic pSmad3L pathway; TGF- $\beta$ and pro-inflammatory cytokines synergistically enhance collagen synthesis by activated HSC via the $\mathrm{pSmad} 2 \mathrm{~L} / \mathrm{C}$ and $\mathrm{pSmad} 3 \mathrm{~L} / \mathrm{C}$ pathways. An important issue is the requirement of particular Smads in the regulation of gene-specific transcriptional responses. In this regard, data from $S m a d 3^{-/-}$mice indicate that $S m a d 3$ regulates epithelial cell growth, whereas Smad2 principally mediates the ECM responses in mesenchymal cells (Ashcroft et al. 1999). Moreover, R-Smad phosphoisoform-mediated signals merit further consideration with regard to different R-Smad signaling between epithelial and mesenchymal cells.

TGF- $\beta$ signaling shared in common between affected hepatocytes and MFB in chronic liver disorders has received less attention. During the progression of chronic liver diseases, pre-neoplastic hepatocytes persistently affected by TGF- $\beta$ together with pro-inflammatory cytokines come to exhibit the same oncogenic (mitogenic) pSmad3L and fibrogenic $\mathrm{pSmad} 2 \mathrm{~L} / \mathrm{C}$ signaling as do MFB, thereby accelerating liver fibrosis, while increasing the risk of HCC. Our model can be recognized as a crucial molecular mechanism by which the vast majority of HCC cases arise in the context of established fibrosis or cirrhosis (Thorgeirsson and Grisham 2002). Thus, the Smad phosphoisoform functions as an important orchestrator of the human chronic inflammation-fibrosis-HCC axis (Elsharkawy and Mann 2007).

Most of the information that we possess has been obtained by studying cells in culture and by examining samples from animals and human patients. Ultimately, we need to examine whether domain-specific phosphorylation of R-Smad is essential for hepatic fibro-carcinogenesis. Conditional knockout mice selectively altered with respect to domain-specific phosphorylation will provide definitive information about RSmad phosphoisoform pathways and gene targets that involve hepatic fibro-carcinogenesis (research currently underway). This information is also critical for planning the use of 
domain-specific phosphorylation inhibitors to treat other fibrotic diseases.

Chronic hepatitis $\mathrm{B}$ and $\mathrm{C}$ can be cured if patients are treated with antiviral therapy that ceases chronic inflammation by eradicating hepatic HBV and HCV populations. Multiple prospective and retrospective analyses have suggested that the successful therapy of chronic hepatitis can improve liver fibrosis accompanied by a reduction of HCC incidence (Yoshida et al. 1999; Shiratori et al. 2000). Prevention appears to be most effective when therapy is given before the development of cirrhosis. In chronic viral hepatitis, HCC occurrence clearly depends on the presence of chronic inflammation. Many patients with cirrhosis have evolved beyond a dependence on inflammation, because their hepatocytes have acquired genetic and epigenetic carcinogenic properties. We are presently carrying out several trials to determine whether antiviral therapy can decrease liver fibrosis and lower HCC incidence. The trials will have a bearing upon important questions with regard to the relative participation in fibro-carcinogenesis of inflammation-dependent and oncogene-dependent Smad phosphoisoform signaling in HBV- and HCV-related chronic liver disorders. In the trials, pathologic analyses with domain-specific phospho-Smad Abs, together with clinical data, will evaluate the benefits of antiviral therapy that decreases the stimulation of the inflammation-dependent Smad phosphoisoform pathway.

Acknowledgements We are grateful to various members of the Kansai Medical University Liver Group for critical reading of the manuscript. We recognize many outstanding published contributions of investigators in the field of liver fibrosis and carcinogenesis. We apologize to those researchers whose work is not included in this review because of space limitations.

Open Access This article is distributed under the terms of the Creative Commons Attribution Noncommercial License which permits any noncommercial use, distribution, and reproduction in any medium, provided the original author(s) and source are credited.

\section{References}

Akira S, Takeda K (2004) Toll-like receptor signalling. Nat Rev Immunol 4:499-511

Alarcón C, Zaromytidou AI, Xi Q, Gao S, Yu J, Fujisawa S, Barlas A, Miller AN, Manova-Todorova K, Macias MJ, Sapkota G, Pan D, Massagué J (2009) Nuclear CDKs drive Smad transcriptional activation and turnover in BMP and TGF- $\beta$ pathways. Cell 139:757-769

Arany PR, Rane SG, Roberts AB (2008) Smad3 deficiency inhibits Vras-induced transformation by suppression of JNK MAPK signaling and increased farnesyl transferase inhibition. Oncogene 27:2507-2512

Arthur MJ (2000) Fibrogenesis. II. Metalloproteinases and their inhibitors in liver fibrosis. Am J Physiol Gastrointest Liver Physiol 279:G245-G249

Ashcroft GS, Yang X, Glick AB, Weinstein M, Letterio JL, Mizel DE, Anzano M, Greenwell-Wild T, Wahl SM, Deng C, Roberts AB
(1999) Mice lacking Smad3 show accelerated wound healing and an impaired local inflammatory response. Nat Cell Biol 1:260 266

Bataller R, Brenner DA (2005) Liver fibrosis. J Clin Invest 115:209218

Bellam N, Pasche B (2010) TGF- $\beta$ signaling alterations and colon cancer. Cancer Treat Res 155:85-103

Brown JD, DiChiara MR, Anderson KR, Gimbrone MA Jr, Topper JN (1997) MEKK-1, a component of the stress (stress-activated protein kinase/c-Jun N-terminal kinase) pathway, can selectively activate Smad2-mediated transcriptional activation in endothelial cells. J Biol Chem 274:8797-8805

Burch ML, Yang SN, Ballinger ML, Getachew R, Osman N, Little PJ (2010) TGF- $\beta$ stimulates biglycan synthesis via p38 and ERK phosphorylation of the linker region of Smad2. Cell Mol Life Sci 67:2077-2090

Caestecker MP de, Parks WT, Frank CJ, Castagnino P, Bottaro DP, Roberts AB, Lechleider RJ (1998) Smad2 transduces common signals from receptor serine-threonine and tyrosine kinases. Genes Dev 12:1587-1592

Date M, Matsuzaki K, Matsushita M, Sakitani K, Shibano K, Okajima A, Yamamoto C, Ogata N, Okumura T, Seki T, Kubota Y, Kan M, McKeehan WL, Inoue K (1998) Differential expression of transforming growth factor- $\beta$ and its receptors in hepatocytes and nonparenchymal cells of rat liver after $\mathrm{CCl} 4$ administration. J Hepatol 28:572-581

Date M, Matsuzaki K, Matsushita M, Tahashi Y, Sakitani K, Inoue K (2000a) Differential regulation of activin A for hepatocyte growth and fibronectin synthesis in rat liver injury. J Hepatol $32: 251-260$

Date M, Matsuzaki K, Matsushita M, Tahashi Y, Furukawa F, Inoue K (2000b) Modulation of transforming growth factor $\beta$ function in hepatocytes and hepatic stellate cells in rat liver injury. Gut 46:719-724

Derynck R, Akhurst RJ (2007) Differentiation plasticity regulated by TGF- $\beta$ family proteins in development and disease. Nat Cell Biol 9:1000-1004

Derynck R, Miyazono K (2008) The TGF- $\beta$ signaling. Cold Spring Harbor Laboratory, Cold Spring Harbor, NY

Derynck R, Zhang YE (2003) Smad-dependent and Smad-independent pathways in TGF- $\beta$ family signaling. Nature 425:577-584

Dooley S, Hamzavi J, Ciuclan L, Godoy P, Ilkavets I, Ehnert S, Ueberham E, Gebhardt R, Kanzler S, Geier A, Breitkopf K, Weng H, Mertens PR (2008) Hepatocyte-specific Smad7 expression attenuates TGF- $\beta$-mediated fibrogenesis and protects against liver damage. Gastroenterology 135:642-659

Eddy AA (2009) Serine proteases, inhibitors and receptors in renal fibrosis. Thromb Haemost 101:656-664

Eitzman DT, McCoy RD, Zheng X, Fay WP, Shen T, Ginsburg D, Simon RH (1996) Bleomycin-induced pulmonary fibrosis in transgenic mice that either lack or overexpress the murine plasminogen activator inhibitor-1 gene. J Clin Invest 97:232237

El-Serag HB, Rudolph KL (2007) Hepatocellular carcinoma: epidemiology and molecular carcinogenesis. Gastroenterology 132:2557-2576

Elsharkawy AM, Mann DA (2007) Nuclear factor-kB and the hepatic inflammation-fibrosis-cancer axis. Hepatology 46:590-597

Engel ME, McDonnell MA, Law BK, Moses HL (1999) Interdependent SMAD and JNK signaling in transforming growth factor- $\beta$ mediated transcription. J Biol Chem 274:37413-37420

Fausto N, Campbell JS, Riehle KJ (2006) Liver regeneration. Hepatology 43:S45-S53

Felsher DW (2004) Reversibility of oncogene-induced cancer. Curr Opin Genet Dev 14:37-42

Friedman SL (2010) Evolving challenges in hepatic fibrosis. Nat Rev Gastroenterol Hepatol 7:425 
Funaba M, Zimmerman CM, Mathews LS (2002) Modulation of Smad2mediated signaling by extracellular signal-regulated kinase. J Biol Chem 277:41361-41368

Furukawa F, Matsuzaki K, Mori S, Tahashi Y, Yoshida K, Sugano Y, Yamagata $\mathrm{H}$, Matsushita $\mathrm{M}$, Seki T, Inagaki $\mathrm{Y}$, Nishizawa $\mathrm{M}$, Fujisawa J, Inoue K (2003) p38 MAPK mediates fibrogenic signal through Smad3 phosphorylation in rat myofibroblasts. Hepatology 38:879-889

Glick AB, Weinberg WC, Wu IH, Quan W, Yuspa SH (1996) Transforming growth factor $\beta 1$ suppresses genomic instability independent of a G1 arrest, p53, and Rb. Cancer Res 56:36453650

Gotzmann J, Fischer AN, Zojer M, Mikula M, Proell V, Huber H, Jechlinger M, Waerner T, Weith A, Beug H, Mikulits W (2006) A crucial function of PDGF in TGF- $\beta$-mediated cancer progression of hepatocytes. Oncogene 25:3170-3185

Gressner OA (2009) Less Smad2 is good for you! A scientific update on coffee's liver benefits. Hepatology 50:970-978

Gressner OA, Lahme B, Demirci I, Gressner AM, Weiskirchen R (2007) Differential effects of TGF- $\beta$ on connective tissue growth factor (CTGF/CCN2) expression in hepatic stellate cells and hepatocytes. J Hepatol 47:699-710

Grimm OH, Gurdon JB (2002) Nuclear exclusion of Smad2 is a mechanism leading to loss of competence. Nat Cell Biol 4:519522

Grivennikov SI, Greten FR, Karin M (2010) Immunity, inflammation, and cancer. Cell 140:883-899

Guo X, Wang XF (2009) Signaling cross-talk between TGF- $\beta / B M P$ and other pathways. Cell Res 19:71-88

Ha H, Oh EY, Lee HB (2009) The role of plasminogen activator inhibitor 1 in renal and cardiovascular diseases. Nat Rev Nephrol 5:203-211

Hamajima H, Ozaki I, Zhang H, Iwane S, Kawaguchi Y, Eguchi Y, Matsuhashi S, Mizuta T, Matsuzaki K, Fujimoto K (2009) Modulation of the transforming growth factor- $\beta 1$-induced Smad phosphorylation by the extracellular matrix receptor beta1integrin. Int J Oncol 35:1441-1447

Hayashida T, Caestecker M de, Schnaper HW (2003) Cross-talk between ERK MAP kinase and Smad signaling pathways enhances TGF- $\beta$-dependent responses in human mesangial cells. FASEB J 17:1576-1578

Haybaeck N, Zeller MJ, Wolf A, Weber U, Wagner MO, Kurrer J, Bremer G, Iezzi RG, Clavien PA et al (2009) A lymphotoxindriven pathway to hepatocellular carcinoma. Cancer Cell 16:295308

He G, Karin M (2011) NF-kB and STAT3 - key players in liver inflammation and cancer. Cell Res 21:159-168

He S, Liu X, Yang Y, Huang W, Xu S, Yang S, Zhang X, Roberts MS (2010) Mechanisms of transforming growth factor $\beta(1) / \mathrm{Smad}$ signalling mediated by mitogen-activated protein kinase pathways in keloid fibroblasts. Br J Dermatol 162:538-546

Heldin CH, Miyazono K, ten Dijke P (1997) TGF- $\beta$ signaling from cell membrane to nucleus through SMAD proteins. Nature 390:465-471

Ho J, Cocolakis E, Dumas VM, Posner BI, Laporte SA, Lebrun JJ (2005) The G protein-coupled receptor kinase-2 is a TGF- $\beta$ inducible antagonist of TGF- $\beta$ signal transduction. EMBO J 24:3247-3258

Hong HY, Jeon WK, Bae EJ, Kim ST, Lee HJ, Kim SJ, Kim BC (2010) 14-3-3 Sigma and 14-3-3 zeta plays an opposite role in cell growth inhibition mediated by transforming growth factor- $\beta$ 1. Mol Cells 29:305-309

Hu PF, Chen H, Zhong W, Lin Y, Zhang X, Chen YX, Xie WF (2009) Adenovirus-mediated transfer of siRNA against PAI-1 mRNA ameliorates hepatic fibrosis in rats. J Hepatol 51:102-113
Inagaki Y, Okazaki I (2007) Emerging insights into transforming growth factor $\beta$ Smad signal in hepatic fibrogenesis. Gut 56:284 292

Hui L, Zatloukal K, Scheuch H, Stepniak E, Wagner EF (2008) Proliferation of human HCC cells and chemically induced mouse liver cancers requires JNK1-dependent p21 downregulation. J Clin Invest 118:3943-3953

Iwano M, Plieth D, Danoff TM, Xue C, Okada H, Neilson EG (2002) Evidence that fibroblasts derive from epithelium during tissue fibrosis. J Clin Invest 110:341-350

Janda E, Lehmann K, Killisch I, Jechlinger M, Herzig M, Downward J, Beug H, Günter S (2002) Ras and TGF- $\beta$ cooperatively regulate epithelial cell plasticity and metastasis: dissection of Ras signaling pathways. J Cell Biol 156:299-313

Javelaud D, Mauviel A (2005) Crosstalk mechanisms between the mitogen-activated protein kinase pathways and Smad signaling downstream of TGF- $\beta$ : implications for carcinogenesis. Oncogene 24:5742-5750

Jiang W, Zhang Y, Wu H, Zhang X, Gan H, Sun J, Chen Q, Guo M, Zhang Z (2010) Role of cross-talk between the Smad2 and MAPK pathways in TGF- $\beta 1$-induced collagen IV expression in mesangial cells. Int J Mol Med 26:571-576

Kamaraju AK, Roberts AB (2005) Role of Rho/ROCK and p38 MAP kinase pathways in transforming growth factor- $\beta$-mediated Smad-dependent growth inhibition of human breast carcinoma cells in vivo. J Biol Chem 280:1024-1036

Kawada N (1997) The hepatic perisinusoidal stellate cell. Histol Histopathol 12:1069-1080

Kawamata S, Matsuzaki K, Murata M, Seki T, Matsuoka K, Iwao Y, Hibi T, Okazaki K (2011) Oncogenic Smad3 signaling induced by chronic inflammation is an early event in ulcerative colitisassociated carcinogenesis. Inflamm Bowel Dis 17:683-695

Kluwe J, Pradere JP, Gwak GY, Mencin A, De Minicis S, Osterreicher CH, Colmenero J, Bataller R, Schwabe RF (2010) Modulation of hepatic fibrosis by c-Jun-N-terminal kinase inhibition. Gastroenterology 138:347-359

Kisseleva T, Brenner DA (2008) Fibrogenesis of parenchymal organs. Proc Am Thorac Soc 5:338-342

Kodama Y, Kisseleva T, Iwaisako K, Miura K, Taura K, De Minicis S, Osterreicher CH, Schnabl B, Seki E, Brenner DA (2009) c-Jun $\mathrm{N}$-terminal kinase-1 from hematopoietic cells mediates progression from hepatic steatosis to steatohepatitis and fibrosis in mice. Gastroenterology 137:1467-1477

Koike K (2002) Hepatocarcinogenesis in hepatitis viral infection: lessons from transgenic mouse studies. J Gastroenterol 37:55-64

Kogure K, Omata W, Kanzaki M, Zhang YQ, Yasuda H, Mine T, Kojima I (1995) A single intraportal administration of follistatin accelerates liver regeneration in partially hepatectomized rats. Gastroenterology 108:1136-1142

Kretzschmar M, Doody J, Timokhina I, Massagué J (1999) A mechanism of repression of TGF- $\beta /$ Smad signaling by oncogenic Ras. Genes Dev 13:804-816

Kwaan HC, McMahon B (2009) The role of plasminogen-plasmin system in cancer. Cancer Treat Res 148:43-66

Lehmann K, Janda E, Pierreux CE, Rytomaa M, Schulze A, McMahon M, Hill CS, Beug H, Downward J (2000) Raf induces TGF- $\beta$ production while blocking its apoptotic but not invasive responses: a mechanism leading to increased malignancy in epithelial cells. Genes Dev 14:2610-2622

Li F, Zeng B, Chai Y, Cai P, Fan C, Cheng T (2009) The linker region of Smad 2 mediates TGF- $\beta$-dependent ERK2-induced collagen synthesis. Biochem Biophys Res Commun 386:289-293

Lin Q, Chen D, Timchenko NA, Medrano EE (2010) SKI promotes Smad3 linker phosphorylations associated with the tumorpromoting trait of TGF- $\beta$. Cell Cycle 9:1684-1689 
Liu F (2006) Smad3 phosphorylation by cyclin-dependent kinases. Cytokine Growth Factor Rev 17:9-17

Llovet JM, Burroughs A, Bruix J (2003) Hepatocellular carcinoma. Lancet 362:1907-1917

Massagué J (2008) TGF- $\beta$ in cancer. Cell 134:215-230

Matsuura I, Denissova NG, Wang G, He D, Long J, Liu F (2004) Cyclin-dependent kinases regulate the antiproliferative function of Smads. Nature 430:226-231

Matsuura I, Chiang KN, Lai CY, He D, Wang G, Ramkumar R, Uchida T, Ryo A, Lu K, Liu F (2010) Pin1 promotes transforming growth factor- $\beta$-induced migration and invasion. J Biol Chem 285:1754 1764

Matsuzaki K (2006) Smad3 phosphoisoform-mediated signaling during sporadic human colorectal carcinogenesis. Histol Histopathol 21:645-662

Matsuzaki K (2009) Modulation of TGF- $\beta$ signaling during progression of chronic liver diseases. Front Biosci 14:2923-2934

Matsuzaki K, Date M, Furukawa F, Tahashi Y, Matsushita M, Sugano Y, Yamashiki N, Nakagawa T, Seki T, Nishizawa M, Fujisawa J, Inoue K (2000a) Regulatory mechanisms for transforming growth factor $\beta$ as an autocrine inhibitor in human hepatocellular carcinoma: implications for roles of Smads in its growth. Hepatology 32:218-227

Matsuzaki K, Date M, Furukawa F, Tahashi Y, Matsushita M, Sakitani K, Yamashiki N, Seki T, Saito H, Nishizawa M, Fujisawa J, Inoue K (2000b) Autocrine stimulatory mechanism by transforming growth factor $\beta$ in human hepatocellular carcinoma. Cancer Res 60:1394-1402

Matsuzaki K, Murata M, Yoshida K, Sekimoto G, Uemura Y, Sakaida N, Kaibori M, Kamiyama Y, Nishizawa M, Fujisawa J, Okazaki K, Seki T (2007) Chronic inflammation associated with hepatitis $\mathrm{C}$ virus infection perturbs hepatic transforming growth factor $\beta$ signaling, promoting cirrhosis and hepatocellular carcinoma. Hepatology 46:48-57

Matsuzaki K, Kitano C, Murata M, Sekimoto G, Yoshida K, Uemura Y, Seki T, Taketani S, Fujisawa J, Okazaki K (2009) Smad2 and Smad3 phosphorylated at both linker and $\mathrm{COOH}$-terminal regions transmit malignant TGF- $\beta$ signal in later stages of human colorectal cancer. Cancer Res 69:5321-5330

Michalopoulos GK (2007) Liver regeneration. J Cell Physiol 213:286-300

Millet C, Yamashita M, Heller M, Yu LR, Veenstra TD, Zhang YE (2009) A negative feedback control of transforming growth factor- $\beta$ signaling by glycogen synthase kinase 3-mediated Smad3 linker phosphorylation at Ser-204. J Biol Chem 284:19808-19816

Mori S, Matsuzaki K, Yoshida K, Furukawa F, Tahashi Y, Yamagata $\mathrm{H}$, Sekimoto G, Seki T, Matsui H, Nishizawa M, Fujisawa J, Okazaki K (2004) TGF- $\beta$ and HGF transmit the signals through JNK-dependent Smad2/3 phosphorylation at the linker regions. Oncogene 23:7416-7429

Moses HL, Yang EY, Pietenpol JA (1990) TGF- $\beta$ stimulation and inhibition of cell proliferation: new mechanistic insights. Cell 63:245-247

Murata M, Matsuzaki K, Yoshida K, Sekimoto G, Tahashi Y, Mori S, Uemura Y, Sakaida N, Fujisawa J, Seki T, Kobayashi K, Yokote K, Koike K, Okazaki K (2009) Hepatitis B virus X protein shifts human hepatic TGF- $\beta$ signaling from tumor-suppression to oncogenesis in early chronic hepatitis B. Hepatology 49:1203-1217

Nagamine Y (2008) Transcriptional regulation of the plasminogen activator inhibitor type 1 -with an emphasis on negative regulation. Thromb Haemost 100:1007-1013

Nagata H, Hatano E, Tada M, Murata M, Kitamura K, Asechi H, Narita M, Yanagida A, Tamaki N, Yagi S, Ikai I, Matsuzaki K, Uemoto S (2009) Inhibition of c-Jun NH2-terminal kinase switches Smad3 signaling from oncogenesis to tumor-suppression in rat hepatocellular carcinoma. Hepatology 49:1944-1953

Oft M, Peli J, Rudaz C, Schwarz H, Beug H, Reichmann E (1996) TGF- $\beta 1$ and Ha-Ras collaborate in modulating the phenotypic plasticity and invasiveness of epithelial tumor cells. Genes Dev 10:2462-2477

Oft M, Akhurst RJ, Balmain A (2002) Metastasis is driven by sequential elevation of H-ras and Smad2 levels. Nat Cell Biol 4:487-494

Omata M, Yoshida H (2004) Prevention and treatment of hepatocellular carcinoma. Liver Transpl 10:S111-S114

Omenetti A, Porrello A, Jung Y, Yang L, Popov Y, Choi SS, Witek RP, Alpini G, Venter J, Vandongen HM, Syn WK, Baroni GS, Benedetti A, Schuppan D, Diehl AM (2008) Hedgehog signaling regulates epithelial-mesenchymal transition during biliary fibrosis in rodents and humans. J Clin Invest 118:3331-3342

Pardali K, Moustakas A (2007) Actions of TGF- $\beta$ as tumor suppressor and pro-metastatic factor in human cancer. Biochim Biophys Acta 1775:21-62

Pikarsky E, Porat RM, Stein I, Abramovitch R, Amit S, Kasem S, Gutkovich-Pyest E, Urieli-Shoval S, Galun E, Ben-Neriah Y (2004) NF-KB functions as a tumour promoter in inflammationassociated cancer. Nature 431:461-466

Pinzani M, Macias-Barragan J (2010) Update on the pathophysiology of liver fibrosis. Expert Rev Gastroenterol Hepatol 4:459-472

Popov Y, Schuppan D (2009) Targeting liver fibrosis: strategies for development and validation of antifibrotic therapies. Hepatology 50:1294-1306

Popov Y, Schuppan D (2010) Epithelial-to-mesenchymal transition in liver fibrosis: dead or alive? Gastroenterology 139:722-725

Rachakonda G, Sekhar KR, Jowhar D, Samson PC, Wikswo JP, Beauchamp RD, Datta PK, Freeman ML (2010) Increased cell migration and plasticity in Nrf2-deficient cancer cell lines. Oncogene 29:3703-3714

Ramadori G, Saile B (2004) Portal tract fibrogenesis in the liver. Lab Invest 84:153-159

Reeves HL, Dack CL, Peak M, Burt AD, Day CP (2000) Stressactivated protein kinases in the activation of rat hepatic stellate cells in culture. J Hepatol 32:465-472

Roberts AB, Sporn MB (1990) The transforming growth factor- $\beta$ s. In: Sporn MB, Roberts AB (eds) Peptide growth factors and their receptors. Springer, Berlin, pp 419-472

Roberts AB, Tian F, Byfield SD, Stuelten C, Ooshima A, Saika S, Flanders KC (2006) Smad3 is key to TGF- $\beta$-mediated epithelialto-mesenchymal transition, fibrosis, tumor suppression and metastasis. Cytokine Growth Factor Rev 17:19-27

Roth-Eichhorn S, Kohl K, Gressner AM (1998) Subcellular localization of (latent) transforming growth factor $\beta$ and the latent TGF- $\beta$ binding protein in rat hepatocytes and hepatic stellate cells. Hepatology 28:1588-1596

Prokova V, Mavridou S, Papakosta P, Kardassis D (2005) Characterization of a novel transcriptionally active domain in the transforming growth factor $\beta$-regulated Smad3 protein. Nucleic Acids Res 33:3708-3721

Saika S, Kono-Saika S, Ohnishi Y, Sato M, Muragaki Y, Ooshima A, Flanders KC, Yoo J, Anzano M, Liu CY, Kao WW, Roberts AB (2004) Smad3 signaling is required for epithelial-mesenchymal transition of lens epithelium after injury. Am J Pathol 164:651663

Sapkota G, Knockaert M, Alarcón C, Montalvo E, Brivanlou AH, Massagué J (2006) Dephosphorylation of the linker regions of Smad1 and Smad2/3 by small C-terminal domain phosphatases has distinct outcomes for bone morphogenetic protein and transforming growth factor- $\beta$ pathways. J Biol Chem 281:40412-40419 
Sasseville M, Ritter LJ, Nguyen TM, Liu F, Mottershead DG, Russell DL, Gilchrist RB (2010) Growth differentiation factor 9 signaling requires ERK1/2 activity in mouse granulosa and cumulus cells. J Cell Sci 123:3166-3176

Schnabl B, Kweon YO, Frederick JP, Wang XF, Rippe RA, Brenner DA (2001) The role of Smad3 in mediating mouse hepatic stellate cell activation. Hepatology 34:89-100

Scholten D, Osterreicher CH, Scholten A, Iwaisako K, Gu G, Brenner DA, Kisseleva T (2010) Genetic labeling does not detect epithelial-to-mesenchymal transition of cholangiocytes in liver fibrosis in mice. Gastroenterology 139:987-998

Sekimoto G, Matsuzaki K, Yoshida K, Mori S, Murata M, Seki T, Matsui H, Fujisawa J, Okazaki K (2007) Reversible Smad-dependent signaling between tumor suppression and oncogenesis. Cancer Res 67:5090-5096

Shi Y, Massagué J (2003) Mechanisms of TGF- $\beta$ signaling from cell membrane to the nucleus. Cell 113:685-700

Shim JH, Xiao C, Paschal AE, Bailey ST, Rao P, Hayden MS, Lee KY, Bussey C, Steckel M, Tanaka N, Yamada G, Akira S, Matsumoto K, Ghosh S (2005) TAK1, but not TAB1 or TAB2, plays an essential role in multiple signaling pathways in vivo. Genes Dev 19:2668-2681

Shirai Y, Kawata S, Tamura S, Ito N, Tsushima H, Takaishi K et al (1994) Plasma transforming growth factor- $\beta 1$ in patients with hepatocellular carcinoma: comparison with chronic liver diseases. Cancer 73:22752279

Shiratori Y, Imazeki F, Moriyama M, Yano M, Arakawa Y, Yokosuka O, Kuroki T, Nishiguchi S, Sata M, Yamada G, Fujiyama S, Yoshida H, Omata M (2000) Histologic improvement of fibrosis in patients with hepatitis $\mathrm{C}$ who have sustained response to interferon therapy. Ann Intern Med 132:517-524

Sugano Y, Matsuzaki K, Tahashi Y, Furukawa F, Mori S, Yamagata H, Yoshida K, Matsushita M, Nishizawa M, Fujisawa J, Inoue K (2003) Distortion of autocrine transforming growth factor $\beta$ signal accelerates malignant potential by enhancing cell growth as well as PAI-1 and VEGF production in human hepatocellular carcinoma cells. Oncogene 22:2309-2321

Suzuki K, Wilkes MC, Garamszegi N, Edens M, Leof EB (2007) Transforming growth factor $\beta$ signaling via Ras in mesenchymal cells requires p21-activated kinase 2 for extracellular signalregulated kinase-dependent transcriptional responses. Cancer Res 67:3673-3682

Tahashi Y, Matsuzaki K, Date M, Yoshida K, Furukawa F, Sugano Y, Matsushita M, Himeno Y, Inagaki Y, Inoue K (2002) Differential regulation of TGF- $\beta$ signal in hepatic stellate cells between acute and chronic rat liver injury. Hepatology 35:49-61

Taub R (2004) Liver regeneration: from myth to mechanism. Nat Rev Mol Cell Biol 5:836-847

Thorgeirsson SS, Grisham JW (2002) Molecular pathogenesis of human hepatocellular carcinoma. Nat Genet 31:339-346

Taura K, Miura K, Iwaisako K, Osterreicher CH, Kodama Y, PenzOsterreicher M, Brenner DA (2010) Hepatocytes do not undergo epithelial-mesenchymal transition in liver fibrosis in mice. Hepatology 51:1027-1036

Tilg H, Kaser A, Moschen AR (2006) How to modulate inflammatory cytokines in liver diseases. Liver Int 26:1029-1039

Tremain R, Marko M, Kinnimulki V, Ueno H, Bottinger E, Glick A (2000) Defects in TGF- $\beta$ signaling overcome senescence of mouse keratinocytes expressing v-Ha-ras. Oncogene 19:1698-1709

Tsukuma H, Hiyama T, Tanaka S, Nakao M, Yabuuchi T, Kitamura T, Nakanishi K, Fujimoto I, Inoue A, Yamazaki H, Kawashima T (1993) Risk factor for hepatocellular carcinoma among patients with chronic liver disease. N Engl J Med 328:1797-1801

Vasilaki E, Siderakis M, Papakosta P, Skourti-Stathaki K, Mavridou S, Kardassis D (2009) Novel regulation of Smad3 oligomerization and DNA binding by its linker domain. Biochemistry 48:8366-8378
Velden JL van der, Alcorn JF, Guala AS, Badura EC, Janssen-Heininger YM (2011) c-Jun N-terminal kinase 1 promotes transforming growth factor- $\{$ beta $\} 1$-induced epithelial-to-mesenchymal transition via control of linker phosphorylation and transcriptional activity of Smad3. Am J Respir Cell Mol Biol 44:571-581

Wakefield LM, Roberts AB (2002) TGF- $\beta$ signaling: positive and negative effects on tumorigenesis. Curr Opin Genet Dev $12: 22-29$

Wang G, Long J, Matsuura I, He D, Liu F (2005) The Smad3 linker region contains a transcriptional activation domain. Biochem J 386:29-34

Wang G, Matsuura I, He D, Liu F (2009) Transforming growth factor$\beta$-inducible phosphorylation of Smad3. J Biol Chem 284:96639673

Weinberg RA (2007) The biology of cancer. Garlang Science, New York Weng HL, Ciuclan L, Liu Y, Hamzavi J, Godoy P, Gaitantzi H, Kanzler S, Heuchel R, Ueberham U, Gebhardt R, Breitkopf K, Dooley S (2007) Profibrogenic transforming growth factor- $\beta$ /activin receptor-like kinase 5 signaling via connective tissue growth factor expression in hepatocytes. Hepatology 46:1257-1270

Wicks SJ, Lui S, Abdel-Wahab N, Mason RM, Chantry A (2000) Inactivation of Smad-transforming growth factor $\beta$ signaling by $\mathrm{Ca}(2+)$-calmodulin-dependent protein kinase II. Mol Cell Biol 20:8103-8111

Wrana JL (2000) Regulation of Smad activity. Cell 100:189-192

Wrighton KH, Lin X, Feng X-H (2009) Phospho-control of TGF- $\beta$ superfamily signaling. Cell Res 19:8-20

Xu J, Lamouille S, Derynck R (2009) TGF- $\beta$-induced epithelial to mesenchymal transition. Cell Res 19:156-172

Yamada Y, Kirillova I, Peschon JJ, Fausto N (1997) Initiation of liver growth by tumor necrosis factor: deficient liver regeneration in mice lacking type I tumor necrosis factor receptor. Proc Natl Acad Sci USA 94:1441-1446

Yamagata H, Matsuzaki K, Mori S, Yoshida K, Tahashi Y, Furukawa F, Sekimoto G, Watanabe T, Uemura Y, Sakaida N, Yoshioka K, Kamiyama Y, Seki T, Okazaki K (2005) Acceleration of Smad2 and Smad3 phosphorylation via c-Jun $\mathrm{NH}(2)$-terminal kinase during human colorectal carcinogenesis. Cancer Res 65:157-165

Yang H, Kyo S, Takatura M, Sun L (2001) Autocrine transforming growth factor $\beta$ suppresses telomerase activity and transcription of human telomerase reverse transcriptase in human cancer cells. Cell Growth Differ 12:119-127

Yang Y, Yang S, Chen M, Zhang X, Zou Y, Zhang X (2008) Compound Astragalus and Salvia miltiorrhiza extract exerts antifibrosis by mediating TGF- $\beta /$ Smad signaling in myofibroblasts. J Ethnopharmacol 118:264-270

Yang YA, Zhang GM, Feigenbaum L, Zhang YE (2006) Smad3 reduces susceptibility to hepatocarcinoma by sensitizing hepatocytes to apoptosis through downregulation of Bcl-2. Cancer Cell 9:445-457

Yasuda H, Mine T, Shibata H, Eto Y, Hasegawa Y, Takeuchi T, Asano S, Kojima I (1993) Activin A: an autocrine inhibitor of initiation of DNA synthesis in rat hepatocytes. J Clin Invest 92:1491-1496

Yoshida H, Shiratori Y, Moriyama M, Arakawa Y, Ide T, Sata M, Inoue O, Yano M, Tanaka M, Fujiyama S, Nishiguchi S, Kuroki T, Imazeki F, Yokosuka O, Kinoyama S, Yamada G, Omata M (1999) Interferon therapy reduces the risk for hepatocellular carcinoma: national surveillance program of cirrhotic and noncirrhotic patients with chronic hepatitis C in Japan. IHIT Study Group. Inhibition of hepatocarcinogenesis by interferon therapy. Ann Intern Med 131:174-181

Yoshida K, Matsuzaki K, Mori S, Tahashi Y, Yamagata H, Furukawa F, Seki T, Nishizawa M, Fujisawa J, Okazaki K (2005) Transforming growth factor- $\beta$ and platelet-derived growth factor signal via c-Jun $\mathrm{N}$-terminal kinase-dependent Smad2/3 phosphorylation 
in rat hepatic stellate cells after acute liver injury. Am J Pathol 166:1029-1039

Yue J, Mulder KM (2000) Requirement of Ras/MAPK pathway activation by transforming growth factor $\beta$ for transforming growth factor $\beta 1$ production in a Smad-dependent pathway. $\mathbf{J}$ Biol Chem 275:30765-30773

Zeisberg M, Yang C, Martino M, Duncan MB, Rieder F, Tanjore H, Kalluri R (2007) Fibroblasts derive from hepatocytes in liver fibrosis via epithelial to mesenchymal transition. J Biol Chem 282:23337-23347

Zhang JY, Tao S, Kimmel R, Khavari PA (2005) CDK4 regulation by TNFR1 and JNK is required for NF-KB-mediated epidermal growth control. J Cell Biol 168:561-566

Zhang JY, Adams AE, Ridky TW, Tao S, Khavari PA (2007) Tumor necrosis factor receptor 1/c-Jun-NH2-kinase signaling promotes human neoplasia. Cancer Res 67:3827-3834 